\title{
Transmission of Monetary Policy with Heterogeneity in Household Portfolios*
}

\author{
Ralph Luetticke ${ }^{\dagger}$
}

June 21, 2018

\begin{abstract}
Monetary policy affects both intertemporal consumption choices and portfolio choices between liquid and illiquid assets. The monetary transmission, in turn, depends on the distribution of marginal propensities to consume and invest. This paper assesses the importance of heterogeneity in these propensities for the transmission of monetary policy in a New Keynesian business cycle model with uninsurable income risk and assets with different degrees of liquidity. Liquidity-constrained households have high propensities to consume but low propensities to invest, which makes consumption more and investment less responsive to monetary shocks compared to complete markets. Redistribution through earnings heterogeneity and the Fisher channel from unexpected inflation further amplifies the consumption response but dampens the investment response.
\end{abstract}

Keywords: Monetary Policy, Heterogeneous Agents, General Equilibrium

JEL-Codes: E21, E32, E52

\footnotetext{
${ }^{*}$ I would like to thank Christian Bayer and Keith Kuester for their invaluable support. I am also grateful for helpful comments and suggestions by Adrien Auclert, Benjamin Born, Tobias Broer, Jürgen von Hagen, Thomas Hintermaier, Fabian Kindermann, Moritz Kuhn, Lien Pham-Dao, Franck Portier, Morten Ravn, and Jirka Slacalek as well as feedback from many seminars. Financial support from the European Research Council under the European Union's Seventh Framework Programme (FTP/2007-2013) / ERC Grant agreement no. 282740 is very gratefully acknowledged.

†University College London, Department of Economics. E-mail: r.luetticke@ucl.ac.uk. Website: http://sites.google.com/site/ralphluetticke/
} 
At least since Tobin (1969) it is well understood that a satisfactory understanding of the monetary transmission mechanism has to go beyond consumption and include household portfolio balances. Changes in the interest rate affect both the intertemporal substitution of consumption and the portfolio composition between liquid nominal claims like government bonds and illiquid real assets like capital. Demand for these different assets translates differently into demand for goods. An increase in the interest rate translates into a shortfall of spending only in so far as higher savings do not increase investment one-for-one. Importantly, households differ enormously in their wealth and portfolio composition. The fraction of savings going into real assets increases in wealth.1 Therefore, monetary transmission depends on both the distribution of the marginal propensities to consume (MPC) and, via households' portfolio choices, the marginal propensities to invest (MPI), which together constitute a household's marginal propensity to spend an additional dollar on goods; see Figure 1.

Figure 1: Heterogeneity in propensities to consume and invest

(a) Marginal propensity to consume

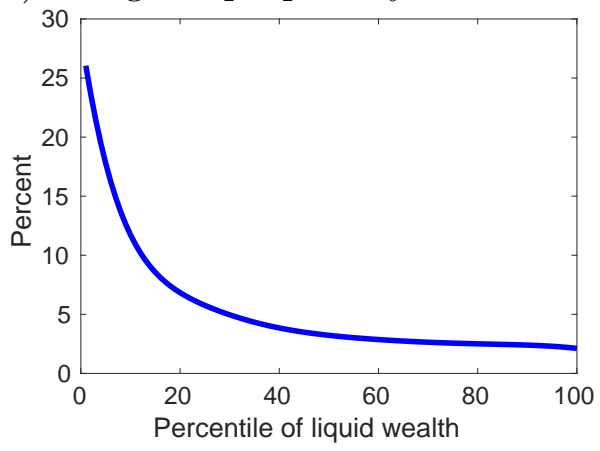

(b) Marginal propensity to invest

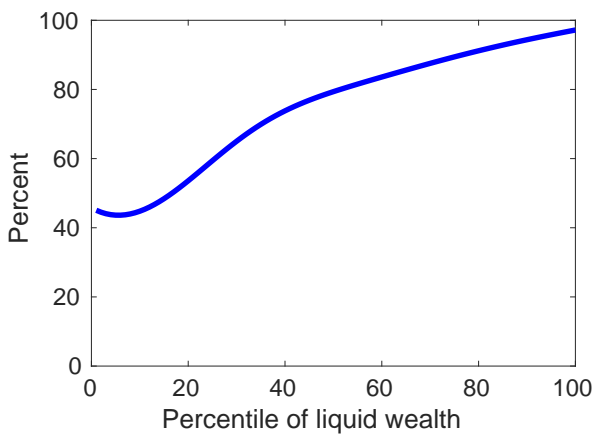

Notes: Marginal propensities to spend an additional dollar on (a) consumption, (b) investment (conditional on adjusting the overall portfolio). Policies by liquid wealth percentile are estimated using a local linear regression technique with a Gaussian kernel and a bandwidth of 0.1 .

This paper assesses the importance of heterogeneity in propensities to consume and invest for the transmission mechanism of monetary policy in the context of a Heterogeneous Agent New Keynesian (HANK) model with asset-market incompleteness, idiosyncratic income risk, and sticky

\footnotetext{
${ }^{1}$ Stocks and businesses account for most of the wealth at the very top of the wealth distribution, while households below median wealth hold a disproportionate share of their wealth in very liquid form like cash and deposits; see Kuhn and Ríos-Rull (2013).
} 
prices. The key feature of the model is to allow for portfolio choice between liquid and illiquid assets in a business-cycle framework. The illiquid asset is real capital. It can only be traded with a certain probability each period but pays a higher return than the liquid asset, which comprises nominal government and household debt and can be traded without frictions. These characteristics enable the model to endogenously generate the distribution of portfolio shares and marginal propensities to consume across households as documented for the United States 2

My first finding is that heterogeneity in household portfolios matters for the aggregate effects of monetary policy. It does so via two channels: 1) On average, MPCs are higher and MPIs lower in comparison to the representative agent version of the model because a sizable fraction of households are liquidity constrained. This reduces the elasticity of investment to changes in the interest rate, while it increases the elasticity of consumption. 2) Heterogeneity in MPCs and MPIs interacts with the redistributive consequences of monetary policy and amplifies this change in elasticities. Quantitatively, investment falls by $50 \%$ less in response to a monetary tightening, while consumption falls by $17 \%$ more such that a monetary shock moves output to a similar extent in the representative and heterogeneous agent version of the model.

A monetary tightening increases income and wealth inequality. $]^{3}$ Households at the top of the wealth distribution benefit from the revaluation of nominal balances, i.e., the Fisher channel, and because a disproportionate share of their income stems from profits, which increase while labor income falls. Wealthy households primarily hold capital and, thus, have a high marginal propensity to invest but low marginal propensity to consume. Higher inequality thereby stabilizes investment after a contractionary monetary policy shock but amplifies the drop in consumption.

Redistribution via the Fisher channel from unexpected inflation is quantitatively important. Its effect depends on the covariance between redistribution and the marginal propensities to consume and invest. The distribution of marginal propensities to spend (MPI+MPC) determines the effect on demand, while the distribution of MPIs matters for investment. I show

\footnotetext{
${ }^{2}$ For evidence on the distribution of MPCs, see the empirical literature on the consumption response to transfers, e.g., Johnson et al. (2006), Parker et al. (2013), or Misra and Surico (2014).

'This is in line with U.S. data. See Coibion et al. (2017), who find higher inequality after contractionary monetary shocks.
} 
that propensities to invest are negatively correlated with inflation-induced redistribution while propensities to spend are positively correlated. When the economy is demand-driven, the Fisher channel amplifies the aggregate effects of monetary shocks through heterogeneity in propensities to spend by $20 \%$. When prices are flexible, in contrast, the Fisher channel only works through investment and leads to an expansion after a monetary tightening.

My second finding is that the monetary transmission mechanism is very different from an economy with complete markets, in which current income and redistribution do not matter. When the rate on liquid assets increases, all else equal, all households optimally increase the liquidity of their portfolios. In equilibrium, however, the monetary tightening causes income to fall, and many households lower their liquid savings to smooth consumption. Portfolio liquidity falls for households with below median wealth, while it increases for wealthy households. For households at the borrowing constraint, consumption falls one-to-one with income. The direct effect of the interest rate cannot explain the sign change in portfolio responses, and quantitatively explains only $20 \%$ of the total change in consumption, while equilibrium effects account for the remaining $80 \%$.

The importance of equilibrium effects contrasts sharply with the standard New Keynesian model that builds on a representative household. In the latter, the direct effects of the interest rate explain close to all of the consumption and investment response. Equilibrium effects are quantitatively unimportant, because they exclusively work through changes in lifetime income, and redistribution is non-existent.

This paper makes an empirical contribution as well. I provide novel evidence for heterogeneity in portfolio responses to monetary shocks. I regress repeated cross-sectional data on household portfolios from the Survey of Consumer Finances (SCF) on monetary policy shocks. $4^{4}$ Sorting households according to percentiles of net wealth, I find that, when rates increase, households below median wealth reduce their portfolio liquidity, while households above median wealth increase portfolio liquidity.

The liquidity friction is key for the model to generate the differential sign and magnitude of the estimated portfolio responses. I calibrate the fraction of households trading capital each quarter to match the capital

\footnotetext{
${ }^{4}$ Wong (2015) and Cloyne et al. (2016) also look at the cross-sectional response to monetary shocks. The first study analyzes the importance of age and the second the importance of housing tenure for the consumption response to monetary shocks using the Consumption Expenditure Survey.
} 
to government debt ratio in U.S. data. As I increase this fraction, fewer households lower their liquid savings in response to a monetary tightening. When capital becomes perfectly liquid, all households increase their portfolio liquidity, which is counterfactual, since $50 \%$ of households lower portfolio liquidity in the data.

The ability of the two-asset model to match the differential portfolio response provides new evidence for the importance of modeling illiquid assets beyond "wealthy-hand-to-mouth" households, which matter for the distribution of marginal propensities to consume (cf. Kaplan and Violante, 2014). The two-asset model implies realistic distributions of marginal propensities to consume and invest. Importantly, investment responds the most to monetary shocks and, hence, understanding investment is key for the monetary transmission.

My findings on the monetary transmission mechanism are complementary to the related work by Kaplan et al. (2018) (KMV). They also decompose the effects of monetary policy into direct and equilibrium effects but focus on the response of consumption to monetary shocks, while I study consumption and investment. The key difference between both models is the portfolio problem: KMV subsume capital and pure profits from monopolistic competition under illiquid assets, and assume that all dividends and profits are paid into the illiquid account. The resulting investment decision implies a counterfactual investment boom after a monetary tightening. In my model, in contrast, aggregate investment follows q-theory..$^{5} \mathrm{I}$ allocate profits to the top $1 \%$ of the income distribution, a group of households that are well-insured and approximately follow the permanent income hypothesis. This has two advantages: 1) It fits the data on the distribution of income, 2) It does not imply counterfactual procyclical earnings risk for $99 \%$ of the population, which would be the case when profits were distributed lump-sum as is done in models with complete markets.

This paper also contributes to the assessment of the Fisher (1933) channel of unexpected inflation as a transmission mechanism of monetary policy. Auclert 2015) studies this channel for the consumption response to monetary shocks and derives a sufficient statistic that depends on the covariance between MPCs and inflation-induced redistribution. In my two-asset

\footnotetext{
${ }^{5}$ Another advantage of random participation in the capital market is its transparency and the ease of implementation, while still being consistent with micro and macro evidence on portfolio allocations and liquidity premia.
} 
model, the Fisher channel works through marginal propensities to both consume and invest, which are negatively correlated and hence potentially cancel each other in terms of the effect on output.

My paper belongs to the recently evolving literature that incorporates market incompleteness and idiosyncratic uncertainty into New Keynesian models ${ }^{6}$ As such, it builds on the New Keynesian literature with its focus on nominal rigidities (cf. Christiano et al., 2005). What my paper and other recent contributions add to this literature is the attempt to endogenize heterogeneity in wealth $]^{7}$ Relative to this literature, my paper provides new evidence for the importance of modeling assets with different degrees of liquidity and is the first to discuss the importance of heterogeneity in propensities to invest for monetary policy.

The remainder of the paper is organized as follows. Section 1 introduces the model, and Section 2 discusses the solution method. Section 3 explains the calibration of the model. Section 4 presents the quantitative results. Section 5 presents the empirical evidence. Section 6 concludes.

\section{Model}

The model economy consists of households, firms, and a government. Households consume, supply labor, obtain profit income, accumulate physical capital, and trade in the bond market. Firms combine capital and labor services to produce goods. The government issues bonds, raises taxes, and purchases goods, while the monetary authority sets the nominal interest rate on bonds. Let me describe each agent in turn 8

\subsection{Households}

There is a continuum of ex-ante identical households of measure one indexed by $i \in[0,1]$. Households are infinitely lived, have time-separable preferences with time-discount factor $\beta$, and derive felicity from consumption $c_{i t}$ and leisure. Households can be workers $\left(h_{i t}>0\right)$ or entrepreneurs

\footnotetext{
${ }^{6}$ See Guerrieri and Lorenzoni (2017), Oh and Reis (2012), Gornemann et al. (2012), Ravn and Sterk (2017), Den Haan et al. (2015), Auclert (2015), Bayer et al. (2015), Werning (2015), McKay and Reis (2016), McKay et al. (2016), and Kaplan et al. (2018). 'Exogenous heterogeneity is well-established in New Keynesian models. See, for example, Galí et al. (2007) and Bilbiie (2008).

${ }^{8}$ This model setup extends previous joint work (c.f. Bayer et al. 2015) and follows the exposition where there is overlay.
} 
$\left(h_{i t}=0\right)$. Transition between both types is exogenous and stochastic, but the fraction of households that are entrepreneurs at any given time $t=0,1,2, \ldots$ is constant. 9

Workers supply labor. Their labor income $w_{t} h_{i t} n_{i t}$ is composed of the wage rate, $w_{t}$, hours worked, $n_{i t}$, and idiosyncratic labor productivity, $h_{i t}$, which evolves according to the following first-order autoregressive process and a fixed probability of transition between the worker and the entrepreneur state:

$$
h_{i t}= \begin{cases}\exp \left(\rho_{h} \log h_{i t-1}+\epsilon_{i t}^{h}\right) & \text { with probability } 1-\zeta \text { if } h_{i t-1} \neq 0 \\ 1 & \text { with probability } \iota \text { if } h_{i t-1}=0 \\ 0 & \text { else, }\end{cases}
$$

with $\epsilon_{i t}^{h} \sim N\left(0, \sigma_{h}\right)$. Entrepreneurs have zero productivity in the labor market, but instead receive an equal share of the economy's total profits $\Pi_{t} \cdot 10$ They pay the same tax rate as workers, $\tau$.

Asset markets are incomplete. Households may only self-insure in nominal bonds, $\tilde{b}_{i t}$, and in capital, $k_{i t}$. Holdings of capital have to be nonnegative, but households may issue nominal bonds up to an exogenously specified limit $\underline{b} \in(-\infty, 0]$. Moreover, trading capital is subject to a friction.

This trading friction only allows a randomly selected fraction of households, $\nu$, to participate in the market for capital each period. All other households obtain dividends, but may only adjust their holdings of nominal bonds. For those households participating in the capital market, the budget constraint reads:

$$
\begin{aligned}
c_{i t}+b_{i t+1}+q_{t} k_{i t+1}= & \frac{R_{t-1}^{b}}{\pi_{t}} b_{i t}+\left(q_{t}+r_{t}\right) k_{i t}+(1-\tau)\left[w_{t} h_{i t} N_{t}+\mathbb{I}_{h_{i t}=0} \Pi_{t}\right], \\
& k_{i t+1} \geq 0, b_{i t+1} \geq \underline{b}
\end{aligned}
$$

where $b_{i t}$ is the real value of nominal bond holdings, $k_{i t}$ are capital holdings,

\footnotetext{
${ }^{9}$ Fixed types of workers and entrepreneurs (or capitalists) without stochastic transitions can be found in Walsh (2014) or Broer et al. (2016), while Romei (2014) uses stochastic transitions.

${ }^{10}$ Attaching the rents in the economy to an exogenously determined group of households instead of distributing them with the factor incomes for capital or labor has the advantage that the factor prices and thus factor supply decisions remain the same as in any standard New Keynesian framework.
} 
$q_{t}$ is the price of capital, $r_{t}$ is the rental rate or "dividend," $R_{t-1}^{b}$ is the gross nominal return on bonds, and $\pi_{t}=\frac{P_{t}}{P_{t-1}}$ is the inflation rate. I denote real bond holdings of household $i$ at the end of period $t$ by $b_{i t+1}:=\frac{\tilde{b}_{i t+1}}{P_{t}}$. There is a wasted intermediation cost, $\bar{R}$, when households resort to unsecured borrowing. Therefore, $R^{b}$ has two parts:

$$
R_{t-1}^{b}\left(b_{i t}, R_{t-1}^{B}\right)= \begin{cases}R_{t-1}^{B} & \text { if } b_{i t} \geq 0 \\ R_{t-1}^{B}+\bar{R} & \text { if } b_{i t}<0\end{cases}
$$

This assumption creates a mass of households with zero unsecured credit but with the possibility to borrow, though at a penalty rate.

For those households that cannot trade in the market for capital the budget constraint simplifies to:

$$
\begin{gathered}
c_{i t}+b_{i t+1}=\frac{R_{t-1}^{b}}{\pi_{t}} b_{i t}+r_{t} k_{i t}+(1-\tau)\left[w_{t} h_{i t} N_{t}+\mathbb{I}_{h_{i t}=0} \Pi_{t}\right], \\
b_{i t+1} \geq \underline{b} .
\end{gathered}
$$

Note that I assume that the depreciation of capital is replaced through maintenance such that the dividend, $r_{t}$, is the net return on capital.

Households have GHH preferences (cf. Greenwood et al., 1988) and maximize the discounted sum of felicity:

$$
V=E_{0} \max _{\left\{c_{i t}, n_{i t}\right\}} \sum_{t=0}^{\infty} \beta^{t} u\left(x_{i t}\right)
$$

where $x_{i t}=c_{i t}-h_{i t} G\left(n_{i t}\right)$ is household $i$ 's composite demand for the physical consumption good $c_{i t}$ and leisure.

The disutility of work, $h_{i t} G\left(n_{i t}\right)$, determines a workers' labor supply given the aggregate wage rate through the first-order condition:

$$
h_{i t} G^{\prime}\left(n_{i t}\right)=(1-\tau) w_{t} h_{i t} .
$$

Under the above assumption, a worker's labor decision does not respond to idiosyncratic productivity $h_{i t}$, but only to the net aggregate wage $(1-\tau) w_{t}$. Thus I can drop the household-specific index $i$, and set $n_{i t}=N_{t} \cdot 11$

\footnotetext{
${ }^{11}$ For the purposes of this paper, GHH preferences and the specific form of the disutility of labor adopted are helpful. They rule out wealth effects on labor supply and more generally make labor supply independent of all idiosyncratic states. As a result, labor supply only depends on the aggregate wage rate, as it does for the representative house-
} 
The Frisch elasticity of aggregate labor supply is constant with $\gamma$ being the inverse elasticity:

$$
G\left(N_{t}\right)=\frac{1}{1+\gamma} N_{t}^{1+\gamma}, \quad \gamma>0
$$

Exploiting the first-order condition on labor supply, the disutility of working can be expressed in terms of the net wage rate:

$$
h_{i t} G\left(N_{t}\right)=h_{i t} \frac{N_{t}^{1+\gamma}}{1+\gamma}=\frac{h_{i t} G^{\prime}\left(N_{t}\right) N_{t}}{1+\gamma}=\frac{(1-\tau) w_{t} h_{i t} N_{t}}{1+\gamma} .
$$

In this way the demand for $x_{i t}$ can be rewritten as:

$$
x_{i t}=c_{i t}-h_{i t} G\left(N_{t}\right)=c_{i t}-\frac{(1-\tau) w_{t} h_{i t} N_{t}}{1+\gamma} .
$$

The budget constraint and the households' planning problem can therefore be expressed in terms of composite good $x_{i t}$.

A household's optimal consumption-savings decision is a non-linear function of that household's asset portfolio $\left\{b_{i t}, k_{i t}\right\}$ and productivity $\left\{h_{i t}\right\}$. Accordingly, the price level $P_{t}$ and aggregate real bonds $B_{t+1}=\frac{\tilde{B}_{t+1}}{P_{t}}$ are functions of the joint distribution $\Theta_{t}$ over idiosyncratic states $\left(b_{t}, k_{t}, h_{t}\right)$. This makes the distribution $\Theta_{t}$ a state variable of the households' planning problem. The distribution $\Theta_{t}$ fluctuates in response to aggregate monetary or total factor productivity shocks. Let $\Omega$ stand in for aggregate shocks.

With this setup, two Bellman equations characterize the dynamic planning problem of a household: $V_{a}$ in the case where the household can adjust its capital holdings and $V_{n}$ otherwise:

$$
\begin{aligned}
V_{a}(b, k, h ; \Theta, \Omega)= & \max _{k^{\prime}, b_{a}^{\prime}} u\left[c\left(b, b_{a}^{\prime}, k, k^{\prime}, h\right)\right]+\beta\left[\nu E V^{a}\left(b_{a}^{\prime}, k^{\prime}, h^{\prime}, \Theta^{\prime}, \Omega^{\prime}\right)\right. \\
& \left.+(1-\nu) E V^{n}\left(b_{a}^{\prime}, k^{\prime}, h^{\prime}, \Theta^{\prime}, \Omega^{\prime}\right)\right] \\
V_{n}(b, k, h ; \Theta, \Omega)= & \max _{b_{n}^{\prime}} u\left[c\left(b, b_{n}^{\prime}, k, k, h\right)\right]+\beta\left[\nu E V^{a}\left(b_{n}^{\prime}, k, h^{\prime}, \Theta^{\prime}, \Omega^{\prime}\right)\right. \\
& \left.+(1-\nu) E V^{n}\left(b_{n}^{\prime}, k, h^{\prime}, \Theta^{\prime}, \Omega^{\prime}\right)\right]
\end{aligned}
$$

In line with this notation, I define the optimal consumption policies for the adjustment and non-adjustment cases as $c_{a}^{*}$ and $c_{n}^{*}$, the nominal bond hold. I thereby isolate the effect of heterogeneity in portfolio responses to monetary shocks. 
holding policies as $b_{a}^{*}$ and $b_{n}^{*}$, and the capital investment policy as $k^{*}$. See Appendix A for the first-order conditions.

\subsection{Intermediate Good Producer}

Intermediate goods are produced with a constant returns to scale production function:

$$
Y_{t}=Z_{t} N_{t}^{\alpha} K_{t}^{(1-\alpha)}
$$

where $Z_{t}$ is total factor productivity (TFP). It follows a first-order autoregressive process:

$$
\log Z_{t}=\rho_{Z} \log Z_{t-1}+\epsilon_{t}^{Z}, \quad \epsilon_{t}^{Z} \sim N\left(0, \sigma_{Z}\right)
$$

Let $M C_{t}$ be the relative price at which the intermediate good is sold to resellers. The intermediate-good producer maximizes profits,

$$
M C_{t} Z_{t} N_{t}^{\alpha} K_{t}^{(1-\alpha)}-w_{t} N_{t}-\left(r_{t}+\delta\right) K_{t}
$$

and faces perfectly competitive markets such that the real wage and the user costs of capital are given by the marginal products of labor and capital:

$$
\begin{aligned}
w_{t} & =\alpha M C_{t} Z_{t}\left(K_{t} / N_{t}\right)^{1-\alpha}, \\
r_{t}+\delta & =(1-\alpha) M C_{t} Z_{t}\left(N_{t} / K_{t}\right)^{\alpha} .
\end{aligned}
$$

\subsection{Resellers}

Resellers differentiate the intermediate good and set prices. I assume price adjustment costs à la Rotemberg (1982). For tractability, I assume that price setting is delegated to a mass-zero group of households (managers) that are risk neutral and compensated by a share in profits. They do not participate in any asset market. Under this assumption, price setting is carried out with a time-constant discount factor. Managers maximize the present value of real profits given the demand for good $j$,

$$
y_{j t}=\left(p_{j t} / P_{t}\right)^{-\eta} Y_{t}
$$


and quadratic costs of price adjustment, i.e., they maximize:

$$
E_{0} \sum_{t=0}^{\infty} \beta^{t} Y_{t}\left\{\left(\frac{p_{j t}}{P_{t}}-M C_{t}\right)\left(\frac{p_{j t}}{P_{t}}\right)^{-\eta}-\frac{\eta}{2 \kappa}\left(\log \frac{p_{j t}}{p_{j t-1}}\right)^{2}\right\}
$$

From the corresponding first-order condition for price setting, it is straightforward to derive the Phillips curve:

$$
\log \left(\pi_{t}\right)=\beta E_{t}\left[\log \left(\pi_{t+1}\right) \frac{Y_{t+1}}{Y_{t}}\right]+\kappa\left(M C_{t}-\frac{\eta-1}{\eta}\right),
$$

where $\pi_{t}$ is the gross inflation rate, $\pi_{t}:=\frac{P_{t}}{P_{t-1}}$, and $M C_{t}$ are the real marginal costs. The price adjustment then creates real costs $\frac{\eta}{2 \kappa} Y_{t} \log \left(\pi_{t}\right)^{2}$.

Since managers are a measure-zero group in the economy, all profits - net of price adjustment costs - go to the entrepreneur-households. In addition, these households also obtain profit income from adjusting the aggregate capital stock. They can transform $I_{t}$ consumption goods into $\Delta K_{t+1}$ capital goods (and back) according to the transformation function:

$$
I_{t}=\frac{\phi}{2}\left(\Delta K_{t+1} / K_{t}\right)^{2} K_{t}+\Delta K_{t+1}
$$

Since they are facing perfect competition in this market, entrepreneurs will adjust the stock of capital until the following first-order condition holds:

$$
q_{t}=1+\phi \Delta K_{t+1} / K_{t}
$$

\subsection{Final Good Producer}

Perfectly competitive final good producers use differentiated goods as input taking input and sell price as given. Final goods are used for consumption and investment. The problem of the representative final good producer is as follows:

$$
\begin{aligned}
& \max _{Y_{t}, y_{j t} \in[0,1]} P_{t} Y_{t}-\int_{0}^{1} p_{j t} y_{j t} d j \\
& \text { s.t. : } Y_{t}=\left(\int_{0}^{1} y_{j t}^{\frac{\eta-1}{\eta}} d j\right)^{\frac{\eta}{\eta-1}},
\end{aligned}
$$

where $y_{j t}$ is the quantity of differentiated good $j$ demanded as input. From the zero-profit condition, the price of the final good is given by $P_{t}=$ $\left(\int_{0}^{1} p_{j t}^{1-\eta} d j\right)^{\frac{1}{1-\eta}}$. 


\subsection{Central Bank and Government}

Monetary policy sets the gross nominal interest rate, $R_{t}^{B}$, according to a Taylor (1993)-type rule that reacts to deviations of inflation from target and exhibits interest rate smoothing:

$$
\frac{R_{t+1}^{B}}{\bar{R}^{B}}=\left(\frac{R_{t}^{B}}{\bar{R}^{B}}\right)^{\rho_{R}}\left(\frac{\pi_{t}}{\bar{\pi}}\right)^{\left(1-\rho_{R}\right) \theta_{\pi}} \epsilon_{t}^{R},
$$

where $\log \epsilon_{t}^{R} \sim N\left(0, \sigma_{R}\right)$ are monetary policy shocks. All else equal, the central bank raises the nominal rate above its steady-state value $R^{B}$ whenever inflation exceeds its target value. 12 The parameter $\rho_{R}$ captures "intrinsic policy inertia."

The fiscal authority decides on government spending, $G_{t}$, raises tax revenues, $T_{t}$, and issues nominal bonds. Let $B_{t+1}$ denote their time $t$ real value. The government budget constraint reads: $B_{t+1}=\frac{R_{t-1}^{B}}{\pi_{t}} B_{i t}+G_{t}-T_{t}$, where real tax revenues are given by $T_{t}=\tau\left[N_{t} W_{t}+\Pi_{t}\right]$. I assume that the government issues bonds according to the rule (c.f. Woodford, 1995):

$$
\frac{B_{t+1}}{\bar{B}}=\left(\frac{B_{t} R_{t}^{B} / \pi_{t}}{\bar{B} \bar{R}^{B} / \bar{\pi}}\right)^{\rho_{B}} .
$$

The coefficient $\rho_{B}$ captures whether and how fast the government seeks to repay its outstanding obligations $B_{t} R_{t}^{B} / \pi_{t}$. For $\rho_{B}<1$ the government actively stabilizes real government debt via adjusting government spending, and for $\rho_{B}=1$ the government rolls over all outstanding debt including interest 13

\subsection{Market Clearing Conditions}

The labor market clears at the competitive wage given in (9); so does the market for capital services if 10 holds. The nominal bond market clears

\footnotetext{
${ }^{12}$ Note that determinacy of the price level in this model does not depend on the Taylor principle $\theta_{\pi}>1$. The economy is non-Ricardian because households value government debt for its consumption-smoothing services. Hence, the standard Taylor principle does not apply here; see Hagedorn (2018).

${ }^{13}$ Adjustment via government spending is the baseline formulation because changing taxes would directly redistribute across households. This also applies to lump-sum taxes in this environment. See Appendix F.5 for robustness to different fiscal rules.
} 
whenever the following equation holds:

$$
B_{t+1}=\int\left[\nu b_{a}^{*}(b, k, h)+(1-\nu) b_{n}^{*}(b, k, h)\right] \Theta_{t}(b, k, h) d b d k d h .
$$

Last, the market for capital has to clear:

$$
\begin{aligned}
q_{t} & =1+\phi \frac{K_{t+1}-K_{t}}{K_{t}} \\
K_{t+1} & =\int\left[\nu k^{*}(b, k, h)+(1-\nu) k(b, k, h)\right] \Theta_{t}(b, k, h) d b d k d h,
\end{aligned}
$$

where the first equation stems from competition in the production of capital goods, and the second equation defines the aggregate supply of funds from households. The goods market then clears due to Walras' law, whenever labor, bond, and capital markets clear.

\subsection{Recursive Equilibrium}

A recursive equilibrium is a set of policy functions $\left\{c_{a}^{*}, c_{n}^{*}, b_{a}^{*}, b_{n}^{*}, k^{*}\right\}$, value functions $\left\{V_{a}, V_{n}\right\}$, pricing functions $\left\{r, R^{B}, w, \pi, q\right\}$, aggregate bonds, capital, and labor supply functions $\{B, K, N\}$, distributions $\Theta_{t}$ over individual asset holdings and productivity, and a perceived law of motion $\Gamma$, such that

1. Given $V_{a}, V_{n}, \Gamma$, prices, and distributions, the policy functions solve the households' planning problem, and given prices, distributions, and the policy functions, the value functions $\left\{V_{a}, V_{n}\right\}$ are a solution to the Bellman equations (7).

2. The labor, the final-goods, the bond, the capital, and the intermediategoods markets clear, i.e., (9), (13), 18), and (19) hold.

3. The actual law of motion and the perceived law of motion $\Gamma$ coincide, i.e., $\Theta^{\prime}=\Gamma\left(\Theta, \Omega^{\prime}\right)$.

\section{Numerical Implementation}

The dynamic program (7) and hence the recursive equilibrium are not computable, because it involves the infinite dimensional object $\Theta_{t}$. I discretize the distribution $\Theta_{t}$ and represent it by its histogram, a finite dimensional object. 


\subsection{Solving the Households' Planning Problem}

I solve for the households' policy functions by applying an endogenous grid point method as originally developed in Carroll (2006) and extended by Hintermaier and Koeniger (2010), iterating over the first-order conditions. I approximate the idiosyncratic productivity process by a discrete Markov chain with 4 states, using the method proposed by Tauchen (1986). I solve the household policies for 150 points on a log-grid for bonds and for capital.

\section{$2.2 \quad$ Aggregate Fluctuations}

I solve for aggregate dynamics by first-order perturbation around the stationary equilibrium without aggregate shocks as in Reiter (2009). To reduce the dimensionality of the problem I follow Bayer et al. (2015) and approximate the three-dimensional distribution $\Theta_{t}$ by a distribution that has a fixed copula and time-varying marginals and the value function and its derivatives by a sparse polynomial around their stationary equilibrium solutions. Appendix $\mathrm{B}$ provides more details on the algorithm and its numerical accuracy.

\section{Calibration}

I calibrate the model to the U.S. economy over the time period 1983Q1 to 2007Q4, since I focus on conventional monetary policy. One period in the model is a quarter. Table 1 shows the targeted moments of the wealth distribution, and Table 2 summarizes the calibration. In detail, I choose the parameter values as follows, with all parameters reported for the quarterly frequency of the model.

\subsection{Households}

I assume that the felicity function is of constant-relative-risk-aversion form: $u(x)=\frac{1}{1-\xi} x^{1-\xi}$, where $\xi=4$, as in Kaplan and Violante (2014). The inverse Frisch elasticity of labor supply is 0.75 , in line with estimates by Chetty et al. (2011). The time-discount factor, $\beta=0.98$, and the capital market participation frequency, $\nu=0.065$, are jointly calibrated to match 
Table 1: Targeted moments of the wealth distribution

\begin{tabular}{lcccl}
\hline \hline Targets & Model & Data & Source & Parameter \\
\hline Mean illiquid assets (K/Y) & 2.86 & 2.86 & NIPA & Discount factor \\
Mean liquidity (B/K) & 0.09 & 0.09 & SCF & Participation frequency \\
Gini total wealth & 0.78 & 0.78 & SCF & Fraction of entrepreneurs \\
Fraction borrowers & 0.16 & 0.16 & SCF & Borrowing penalty \\
\hline
\end{tabular}

the ratio of capital and government bonds to output ${ }^{14}$ I equate capital to all capital goods relative to nominal GDP. The annual capital-to-output ratio is therefore $286 \%$. This implies an annual real return on capital of about $4.5 \%$. I equate government bonds to the outstanding government debt held by private domestic agents, which implies an annual bonds-tocapital ratio of $9 \%$.

I set the borrowing limit in bonds, $\underline{b}$, to half of the average quarterly income and choose the penalty rate for unsecured borrowing, $\bar{R}$, such that $16 \%$ of households have negative net nominal positions as in the Survey of Consumer Finances 1983-2007 15

I calibrate the transitions in and out of the entrepreneur state to capture the distribution of wealth in the U.S. economy. For simplicity, I assume that the probability of becoming an entrepreneur is the same for workers independent of their labor productivity and that, once they become workers again, they start with median productivity. I calibrate the probability of leaving the entrepreneurial state to $1 / 16$ per quarter following the numbers that Guvenen et al. (2014) report on the probability of dropping out of the top $1 \%$ income group in the U.S. (see their Table 2 , roughly $25 \%$ p.a.). In order to match a wealth Gini index of 0.78 , this implies that roughly $1 \%$ of households are entrepreneurs. ${ }^{16}$

I set the quarterly standard deviation of persistent shocks to idiosyncratic labor productivity to 0.06 and the quarterly autocorrelation to 0.98

\footnotetext{
${ }^{14}$ The participation frequency of $6.5 \%$ per quarter is higher than in the optimal participation framework of Kaplan and Violante (2014). They find a participation frequency of $4.5 \%$ for working households given a fixed-adjustment cost of $\$ 500$.

${ }^{15}$ Appendix C.2 provides a more detailed discussion of the cross-sectional data.

${ }^{16}$ This mimics the U.S. income distribution. According to the Congressional Budget Office, the top $1 \%$ of the income distribution receives about $30 \%$ of their income from financial income, a much larger share than any other segment of the population.
} 
- both standard values in the literature (c.f. Storesletten et al., 2004).

\subsection{Production Sectors}

The labor and capital share including profits $(2 / 3$ and $1 / 3)$ align with longrun U.S. averages. The persistence of the TFP shock is set to $\rho_{Z}=0.9$. The standard deviation of the TFP shock, $\sigma_{Z}=0.007$, is calibrated to make the model match the standard deviation of H-P-filtered U.S. output.

To calibrate the parameters of the resellers' problem, I use standard values for markup and price stickiness that are widely employed in the New Keynesian literature (c.f. Christiano et al., 1999). The Phillips curve parameter $\kappa$ implies an average price duration of 4 quarters, assuming flexible capital at the firm level. The steady-state marginal costs, $\frac{\eta-1}{\eta}=$ 0.95, imply a markup of $5 \%$. I calibrate the adjustment cost of capital, $\phi=8.5$, to match a relative investment volatility of 3 in response to TFP shocks - a standard value for U.S. data.

\subsection{Central Bank and Government}

I set the inflation rate to zero and the real return on bonds to $2.5 \%$ in line with the average federal funds rate in the U.S. in real terms from 1983 to 2007. Clarida et al. (2000) provide an estimate for the parameter governing interest rate smoothing, $\rho_{R}=0.8$, while the central bank's reaction to deviations of inflation from target is standard, $\theta_{\pi}=1.5$. The standard deviation of the monetary policy shock, $\sigma_{D}$, is 36 basis points annualized, which corresponds to the average quarterly shock as identified by the narrative approach (c.f. Wieland and Yang, 2016).

The government levies a proportional tax on labor income and profits to finance government spending and interest expense on debt. A tax rate of $\tau=0.3$ closes the budget constraint given the interest expense and a government-spending-to-GDP ratio of $20 \%$ in the steady state. Government spending, in turn, follows a fiscal rule similar to Woodford (1995) or Bi et al. (2013). Specifically, I set $\rho_{B}=0.98$ so that most of the adjustment goes through government debt and future government spending adjusts to bring debt back to its steady-state value. Appendix F.5 provides robustness checks. 
Table 2: Calibrated parameters

Parameter Value Description Target

\begin{tabular}{lrll}
\hline Households & & & \\
$\beta$ & 0.98 & Discount factor & see Table 1 \\
$\nu$ & $6.5 \%$ & Participation frequency & see Table 1 \\
$\xi$ & 4 & Relative risk aversion & Kaplan and Violante 2014$)$ \\
$\gamma$ & 0.75 & Inv. Frisch elasticity & Chetty et al. \\
$\bar{R}$ & $11 \%$ & Borrowing penalty & see Table 1 \\
$\rho_{h}$ & 0.98 & Persistence of productivity & Standard value \\
$\sigma_{h}$ & 0.06 & STD of innovations & Standard value
\end{tabular}

\section{Intermediate Goods}

$\begin{array}{lrll}\alpha & 70 \% & \text { Share of labor } & \text { Income share labor of } 66 \% \\ \delta & 1.35 \% & \text { Depreciation rate } & \text { NIPA: Fixed assets } \\ \rho_{Z} & 0.9 & \text { Persistence of TFP shock } & \text { Standard value } \\ \sigma_{Z} & 0.007 & \text { STD of TFP shock } & \text { Volatility of output }\end{array}$

\section{Final Goods}

$\begin{array}{lrll}\kappa & 0.09 & \text { Price stickiness } & 4 \text { quarters } \\ \eta & 20 & \text { Elasticity of substitution } & 5 \% \text { markup }\end{array}$

\section{Capital Goods}
$\phi$
8.5 Capital adjustment costs
$\operatorname{STD}(I) / \operatorname{STD}(Y)=3$

\section{Fiscal Policy}

$\begin{array}{lrll}\tau & 0.3 & \text { Tax rate } & G / Y=20 \% \\ \rho_{B} & 0.98 & \text { Reaction to debt } & \text { Autocorrelation of debt }\end{array}$

\section{Monetary Policy}

$\begin{array}{lrll}\Pi & 1 & \text { Inflation } & 0 \% \text { p.a. } \\ R^{B} & 1.0062 & \text { Nominal interest rate } & 2.5 \% \text { p.a. } \\ \theta_{\pi} & 1.5 & \text { Reaction to inflation } & \text { Standard value } \\ \rho_{R} & 0.8 & \text { Interest rate smoothing } & \text { Clarida et al. (2000) } \\ \sigma_{R} & 9 \mathrm{e}-4 & \text { STD of monetary shock } & \text { Wieland and Yang (2016) }\end{array}$

Notes: All values are reported for the quarterly frequency of the model. 


\section{Results}

I first consider the theoretical channels through which monetary policy directly and indirectly affects household decisions in this model. I quantify the direct effect of changes in the interest rate on household consumption and portfolio decisions by solving for individual optimal decisions keeping all other prices and quantities constant. Comparing the direct responses to the change of consumption and portfolios in equilibrium reveals the importance of "indirect" equilibrium changes in prices and income. I then compare the aggregate effects on the economy with heterogeneity in household portfolios to the same economy with a representative household and discuss the importance of heterogeneity in household portfolios for aggregate outcomes 17

\subsection{Transmission Channels of Monetary Policy}

Key for understanding the transmission of monetary policy in any DSGE model is the household consumption-savings decision. The decision problem of households in an incomplete-markets setting differs from that of a representative household because borrowing constraints bind for a fraction of households and the marginal value of liquid assets differs across households. The effect of monetary policy on household decisions, in turn, can be split into direct and indirect effects.

Consider a contractionary monetary policy shock. All else equal, an increase in the nominal interest rate also increases the real return on liquid assets and, thus, the intertemporal relative price of composite consumption of leisure and goods, $X_{t}$, today vs. tomorrow ${ }^{18}$ At the same time, a higher return on liquid assets induces households to rebalance their portfolios towards the liquid asset - reducing savings in illiquid capital. Moreover, higher interest payments on liquid assets imply an income effect that is

\footnotetext{
${ }^{17}$ The representative household version of the model does not feature limited participation in the capital market because households are perfectly insured through statecontingent claims. I keep the parameters of the model unchanged to isolate the effect of heterogeneity in household portfolios on the transmission of monetary policy.

${ }^{18}$ Recall that the household problem can be expressed in terms of composite consumption $X_{t}$ with GHH preferences: $x_{i t}=c_{i t}-\frac{(1-\tau) w_{t} h_{i t} N_{t}}{1+\gamma}$. It is therefore the intertemporal allocation of composite consumption that matters for the household in this model.
} 
Figure 2: Partial equilibrium - Individual response to a monetary shock

(a) Consumption response $\Delta \log c_{i t}$

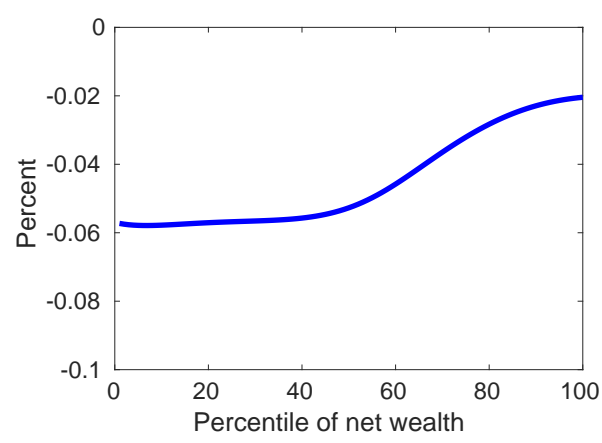

(c) Bond response $\Delta \log b_{i t}$

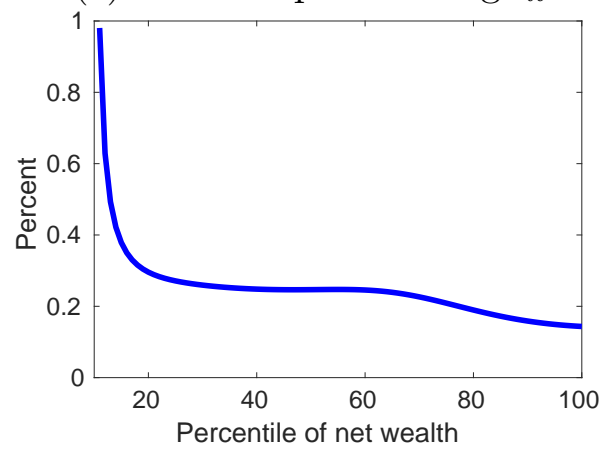

(b) Portfolio liquidity $\Delta\left(b_{i t} / k_{i t}\right)$

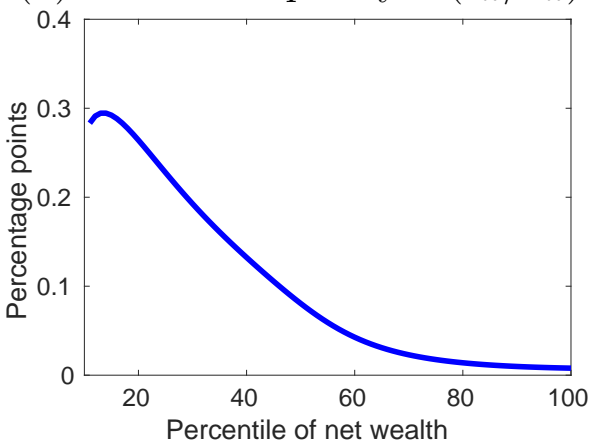

(d) Capital response $\Delta \log k_{i t}$

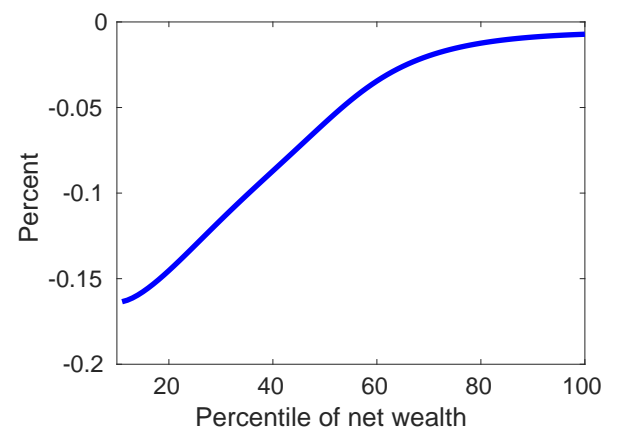

Response of individual consumption and asset demand policies at constant prices and quantities to a 1 standard deviation monetary shock, $\epsilon^{R}=36$ basis points (annualized). Policies by wealth percentile are estimated using a local linear regression technique with a Gaussian kernel and a bandwidth of 0.1. Asset demand policies start at the 11th percentile because poorer households hold negative liquid wealth.

positive or negative depending on a household's net liquid asset position. I refer to the effects of the interest rate change as the direct channel of monetary policy.

Figure 2 shows the individually optimal response across the wealth distribution to an increase in the interest rate by 36 basis points annualized (reverting back according to the inertia in the Taylor rule, $\rho_{R}=0.8$ ) - keeping all other prices and quantities fixed. Consumption falls the most for households with below median wealth. Consumption of wealthy households falls by markedly less because of a positive income effect. All households increase the liquidity of their portfolios, and, if possible, sell illiquid capital to buy liquid bonds. The rebalancing is strongest for households in the 
Figure 3: Portfolio response, $\Delta\left(b_{i t} / k_{i t}\right)$, to a monetary shock in equilibrium

(a) Model

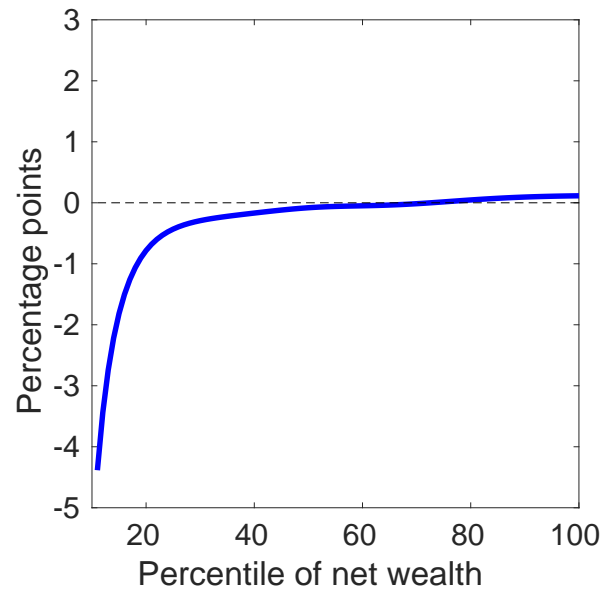

(b) Data

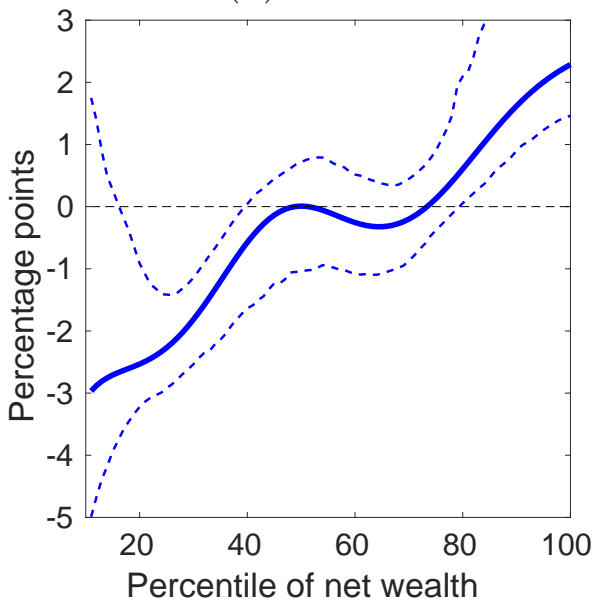

Change in portfolio liquidity after a 1 standard deviation monetary shock, $\epsilon^{R}=36$ basis points (annualized), after 2 years. Policies by wealth percentile are estimated using a local linear regression technique with a Gaussian kernel and a bandwidth of 0.1. Data correspond to the local projection with SCF data as in Section 5 at a horizon of 2 years. Bootstrapped $90 \%$ confidence bands are shown in the dashed lines, based on a non-parametric bootstrap. Plotted from the 11th percentile onwards because poorer households hold negative liquid wealth.

bottom of the wealth distribution.

Since prices are sticky, the decrease in consumption and investment is not completely offset by lower prices, and output falls. Lower output, in turn, decreases income, consumption and investment, which again reduces income and so forth. I refer to the equilibrium changes in income and prices as the indirect effects of monetary policy.

In the complete markets economy, these indirect effects matter for composite consumption only in so far as they change lifetime income, because the consumption path is determined by a sequence of Euler equations and a single lifetime budget constraint. The consumption of final goods, $C_{t}$, and labor supply, $N_{t}$, then follows through the intratemporal consumptionleisure trade-off that solely depends on the wage rate. With incomplete markets, however, current income becomes an important determinant of composite and final-goods consumption because of borrowing constraints.

The quantitative importance of indirect effects becomes apparent in Figure 3. Panel (a) shows the portfolio response 8 quarters after a mon- 
etary tightening (by 36 basis points annualized) in equilibrium. In contrast to Figure 2, portfolio liquidity falls for the majority of households, although the return on liquid assets is higher. Only households in the top $30 \%$ of the wealth distribution increase their portfolio liquidity. These households are well-insured, while wealth-poor households use their liquid savings to smooth consumption. The heterogeneity in household portfolio responses matches the empirical estimates of the portfolio response to monetary shocks from the Survey of Consumer Finances; see Panel (b).

Section 5 discusses the empirical results in more detail. The next section first describes the aggregate effects of monetary shocks in the model with and without complete markets, and then elaborates on the importance of heterogeneous household responses.

\subsection{Equilibrium Effects of a Monetary Policy Shock}

As before, I consider the effect of a monetary surprise that, all else equal, would increase the nominal interest rate on liquid assets by 1 standard deviation, i.e., 36 basis points (annualized), in period 1. Figure 4 compares the responses of the economy with and without heterogeneity in household portfolios.

What stands out immediately is that the output response is almost identical. The initial drop in output is about $0.8 \%$ in both versions of the model. The composition of the output drop, however, is quite different. The fall in consumption is steeper in the economy with heterogeneous households, while the reverse is true for investment. Consumption falls by $17 \%$ more and the total consumption loss over 4 years is 0.35 percentage point higher with incomplete markets. Investment, however, falls by $50 \%$ less when markets are incomplete, which leaves the output response the same 19

Looking at composite consumption $X_{t}$, which abstracts from the interaction between wage rate and consumption inherent in $\mathrm{GHH}$ preferences, makes the difference between both economies even more evident 20 Composite consumption falls in equilibrium five times more when current in-

\footnotetext{
${ }^{19}$ The finding of a lower elasticity of investment to monetary shocks is robust to the assumptions on fiscal policy, allocation of profits, and aggregate capital adjustment costs; see Appendix F

${ }^{20}$ More leisure time decreases the marginal utility of consumption with GHH preferences such that, all else equal, consumption falls with labor supply $N_{t}$.
} 
Figure 4: Aggregate response to a monetary shock
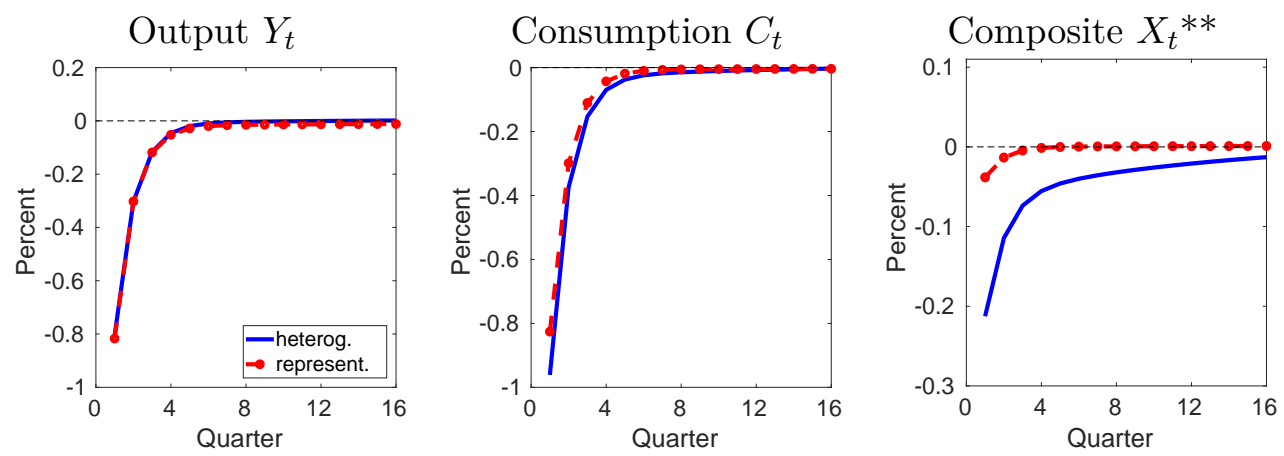

Investment $I_{t}$
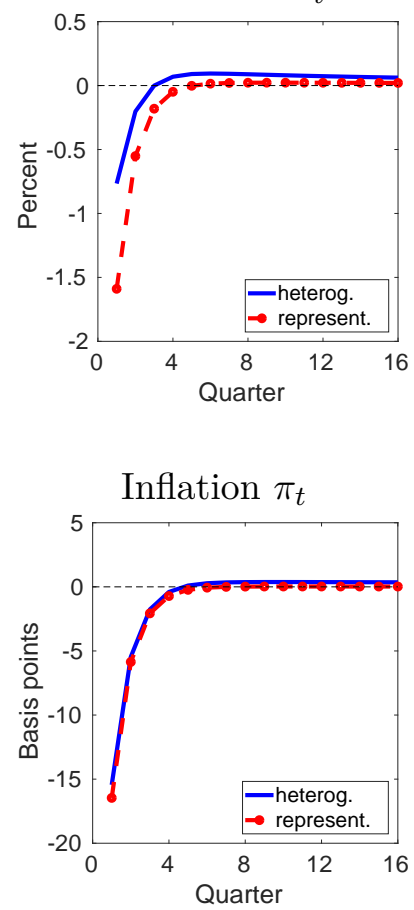

Price of capital $q_{t}$

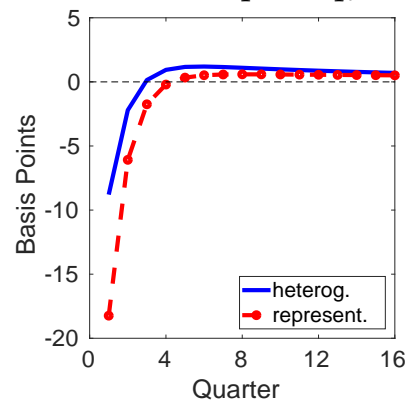

Gov. spending $G_{t}$

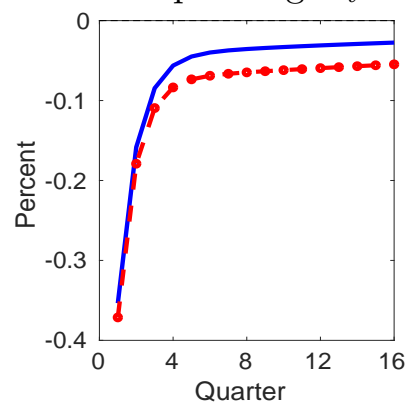

Nominal rate $R_{t}^{B}$

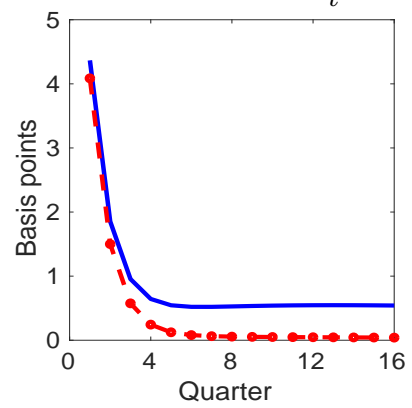

Dividend $r_{t}$

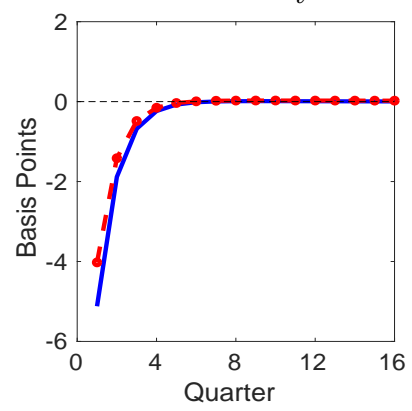

Wages $W_{t}$

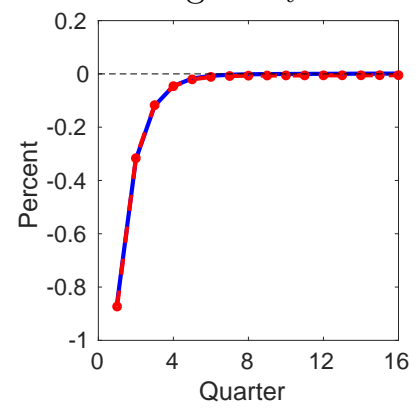

Profits $\Pi_{t}$

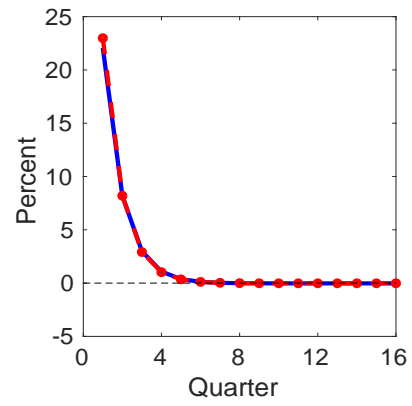

Liquidity premium*

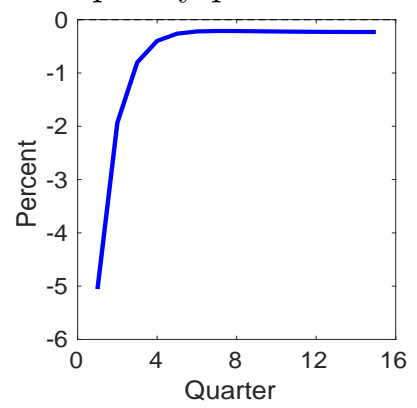

Notes: Impulse responses to a 1 standard deviation monetary policy shock, $\epsilon^{R}=36$ basis points (annualized). Solid line: the model with heterogeneous households. Dashed line: same calibration with a representative household. All rates (dividends, interest, liquidity premium) are not annualized. ${ }^{*} L P=$ $\frac{E_{t} q_{t+1}+r_{t}}{q_{t}}-\frac{R_{t}^{B}}{E_{t} \pi_{t+1}} * * X_{t}=\int\left(c_{i t}-h_{i t} \frac{n_{i t}^{1+\gamma}}{1+\gamma}\right) d i$ 
Table 3: Exposure to monetary shocks by wealth holdings

\begin{tabular}{lcccc}
\hline \hline & \multicolumn{3}{c}{ Income gains/losses } & Capital gains/losses \\
Wealth & Interest & Dividends & Labor/Profit & on real assets \\
quintiles & $\Delta\left(R_{t-1}^{B} / \pi_{t}\right)$ & $\Delta r_{t}$ & $\Delta\left(W_{t} N_{t}+\Pi_{t}\right)$ & $\Delta q_{t}$ \\
\hline & & & & \\
1. & -0.03 & -0.05 & -6.53 & -0.05 \\
2. & 0.25 & -0.16 & -6.12 & -0.27 \\
3. & 0.35 & -0.36 & -5.51 & -0.62 \\
4. & 0.37 & -1.17 & -1.99 & -2.03 \\
5. & 0.44 & -2.49 & 1.61 & -4.33 \\
\hline
\end{tabular}

Notes: On impact gains and losses in percent of within group consumption after a 1 standard deviation monetary policy shock, $\epsilon^{D}=36$ basis points (annualized). Results are expressed in terms of steady-state consumption and averaged by using frequency weights from the steady-state wealth distribution.

come, and not lifetime income, is the relevant constraint, and stays subdued for 16 quarters. The indirect effects through the lifetime budget constraint are of minor importance, and composite consumption is determined by the path of the real rate when markets are complete. Current income, however, responds strongly and so does composite consumption when borrowing constraints bind. Quantitatively, indirect effects explain $80 \%$ of the drop in composite consumption with market incompleteness, while the direct effect through interest rate changes accounts for only 20\%; compare Figure 4 to Figure $22^{21}$

The most important indirect effect comes from the fall in labor income. Wages fall to a similar extent as consumption; see Figure 4 . Table 3 summarizes the gains and losses on each source of income. They are reported relative to the average consumption of each wealth bracket. Labor income for households below median wealth falls by more than $6 \%$ of consumption, while households in the top quintile of the wealth distribution enjoy higher returns on their human capital on average because an disproportionate share are entrepreneurs. They receive profit income that increases while labor income falls. ${ }^{22}$ The top quintile incurs the highest losses on the

\footnotetext{
${ }^{21}$ Looking at consumption of final goods, indirect effects explain about $95 \%$ of the total response because of $\mathrm{GHH}$ preferences. The $\mathrm{GHH}$ effect, however, is also present in the complete-markets setting. It accounts for about $90 \%$ of the response in consumption of final goods there. This is driven by the adopted preference specification and vanishes with additively separable preferences in consumption and leisure.

${ }^{22}$ The results are qualitatively robust to allocating profits lump-sum; see Appendix
} 
Figure 5: Marginal propensities to consume and invest

(a) MPC

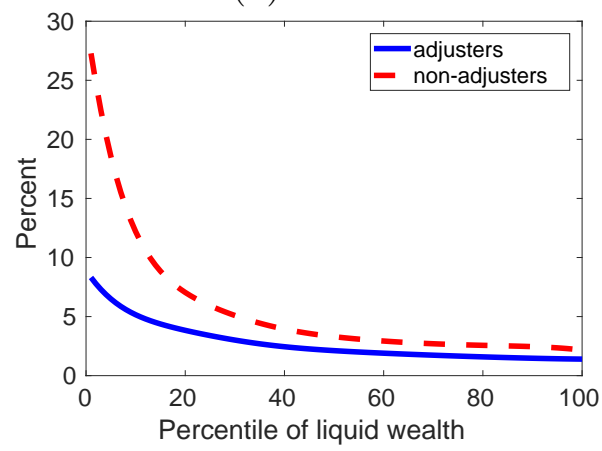

(c) MPC+MPI (MPS)

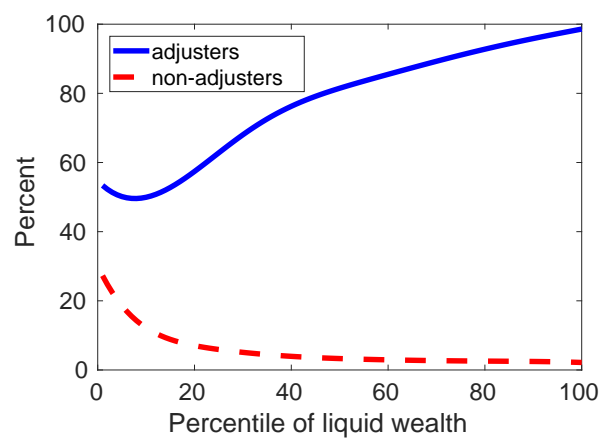

(b) MPI

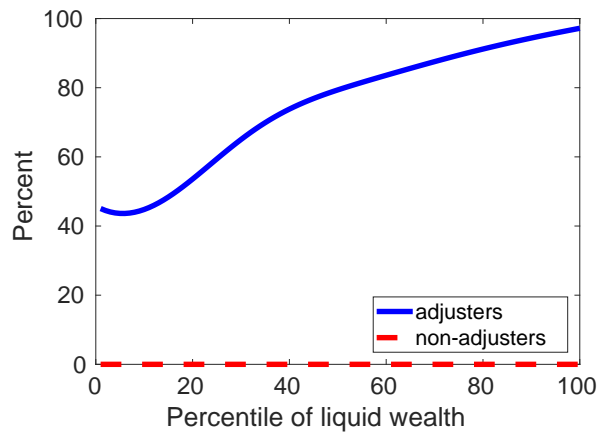

(d) MPC, MPI, and MPS

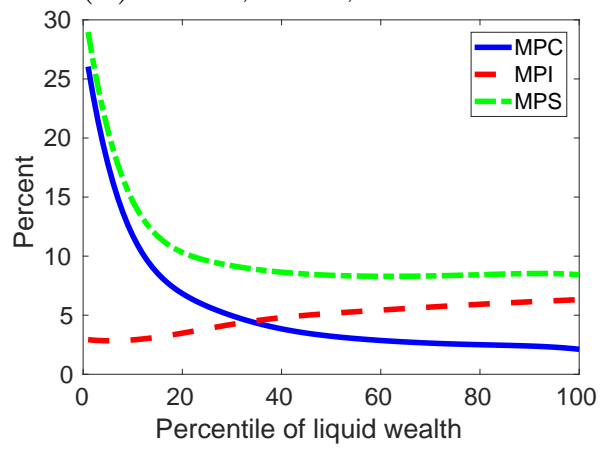

Marginal propensities to spend an additional dollar on (a) consumption, (b) investment, and (c) consumption plus investment for households that can and cannot adjust their illiquid asset position. Panel (d) shows all three propensities (MPC, MPI, MPS) for all households combined. Policies by liquid wealth percentile are estimated using a local linear regression technique with a Gaussian kernel and a bandwidth of 0.1 .

real asset position. However, most of it is caused by lower asset prices that are not completely realized.

The Fisher channel is important as well. Surprise deflation redistributes from borrowers to savers; see the column labeled 'Interest' in Table 3 . On average, borrowers have higher marginal propensities to consume but lower marginal propensities to invest than savers. Figure 5 plots these marginal propensities for each percentile of the liquid wealth distribution. Households close to the borrowing constraint have the highest marginal propensity to consume, around $25 \%$, but the fraction of an additional dollar that goes into investment is less then $5 \%$. Households above median wealth, in contrast, invest twice as much of any additional dollar. The sum of both the 
marginal propensities to consume and invest yields the marginal propensity to spend an additional dollar on goods, which matters for the effect of redistribution on aggregate demand. Panel (d) shows that the marginal propensity to spend is higher for borrowers than savers. Hence, the Fisher channel amplifies the aggregate effects of monetary policy through aggregate demand.

I quantify the Fisher channel by solving a version of the model with real debt, in which inflation-induced redistribution is absent, and find that aggregates fall by roughly $20 \%$ more in the baseline model with nominal debt (Y by $23 \%$ more, C by $22 \%$ more, I by $25 \%$ more). This amplification of the recessionary effects of a monetary tightening depends on prices being sticky. When prices are flexible, heterogeneity in propensities to spend does not matter because any shortfall in spending is offset by firms lowering prices. Only heterogeneity in the marginal propensity to invest matters in this case because it affects the future capital stock. For this reason, a monetary tightening leads to a boom with flexible prices as inflation redistributes from borrowers with low to savers with high marginal propensities to invest.23

The heterogeneity in the marginal propensity to invest is key for understanding the substantially smaller investment response in the full model with heterogeneity in household portfolios in comparison to the model with complete markets ${ }^{24}$ A tightening of monetary conditions increases inequality because it redistributes from borrowers to savers and from households that earn wage income to those that earn profit income. Both channels transfer from the bottom to the top of the wealth distribution and hence increase inequality ${ }^{25}$ Wealthy households have a higher marginal propensity to invest and, thus, stabilize investment demand as they get richer through redistribution.

Figure 6 displays the equilibrium response of household portfolios and consumption to the monetary shock across the wealth distribution on impact. All households that can adjust portfolios sell capital, but capital holdings fall the most for households with below median wealth. Adjusters increase the liquidity of their portfolios, with the highest increase at the 20th percentile of the wealth distribution. The dashed line in Panel (b),

\footnotetext{
${ }^{23}$ See Appendix F.4 for more details.

${ }^{24}$ See Appendix F.1 for the investment response with liquid capital and constant MPIs.

${ }^{25}$ See Appendix E for the response of the Ginis of consumption, income, and wealth. These findings mirror recent empirical evidence by Coibion et al. (2017).
} 
Figure 6: Consumption and portfolio response to a monetary shock

(a) Consumption response $\Delta \log c_{i t}$

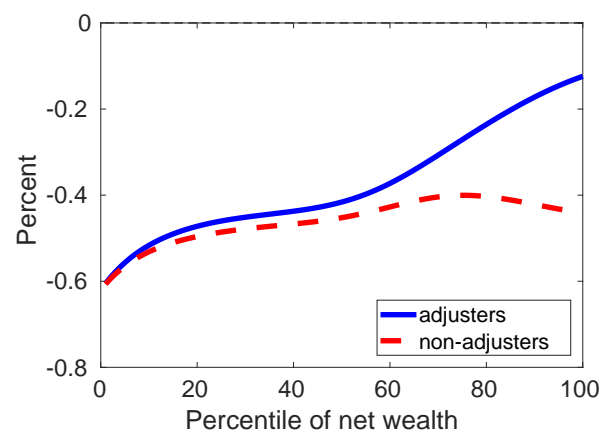

(c) Bond response $\Delta \log b_{i t}$

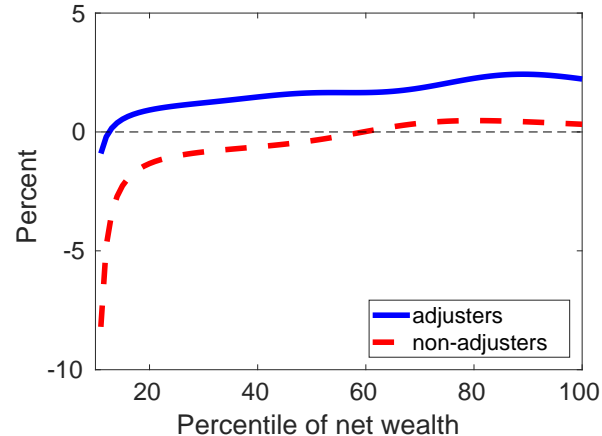

(b) Portfolio liquidity $\Delta\left(b_{i t} / k_{i t}\right)$

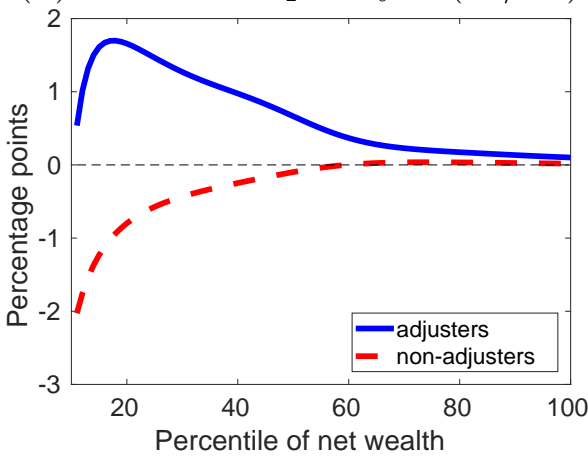

(d) Capital response $\Delta \log k_{i t}$

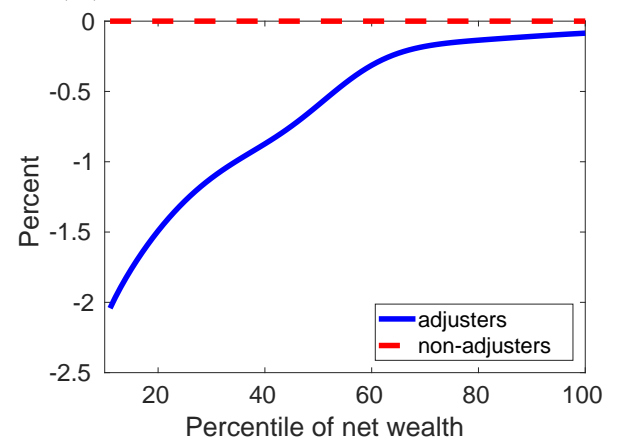

On impact equilibrium response of individual consumption and asset demand policies for households that can and cannot adjust their illiquid asset position to a 1 standard deviation monetary shock, $\epsilon^{R}=36$ basis points (annualized). Policies by wealth percentile are estimated using a local linear regression technique with a Gaussian kernel and a bandwidth of 0.1. Asset demand policies start at the 11th percentile because poorer households hold negative liquid wealth.

however, reveals that portfolio liquidity falls for a large fraction of households that cannot adjust their portfolios. Liquid bond holdings fall the most, about $-8 \%$, for wealth-poor households who see the largest decline in consumption as well. Combining adjusters and non-adjusters, the liquidity ratio falls for households with below median wealth.

To generate this sign difference in the portfolio response to monetary shocks, the liquidity friction and sizable indirect effects through the period budget constraint are key. In partial equilibrium, when only the return on liquid assets increases, all households increase portfolio liquidity; see Figure 2. In equilibrium, when current income falls, most households use their liquid savings to smooth consumption. This holds true even for longer 
Figure 7: Portfolio response counterfactuals
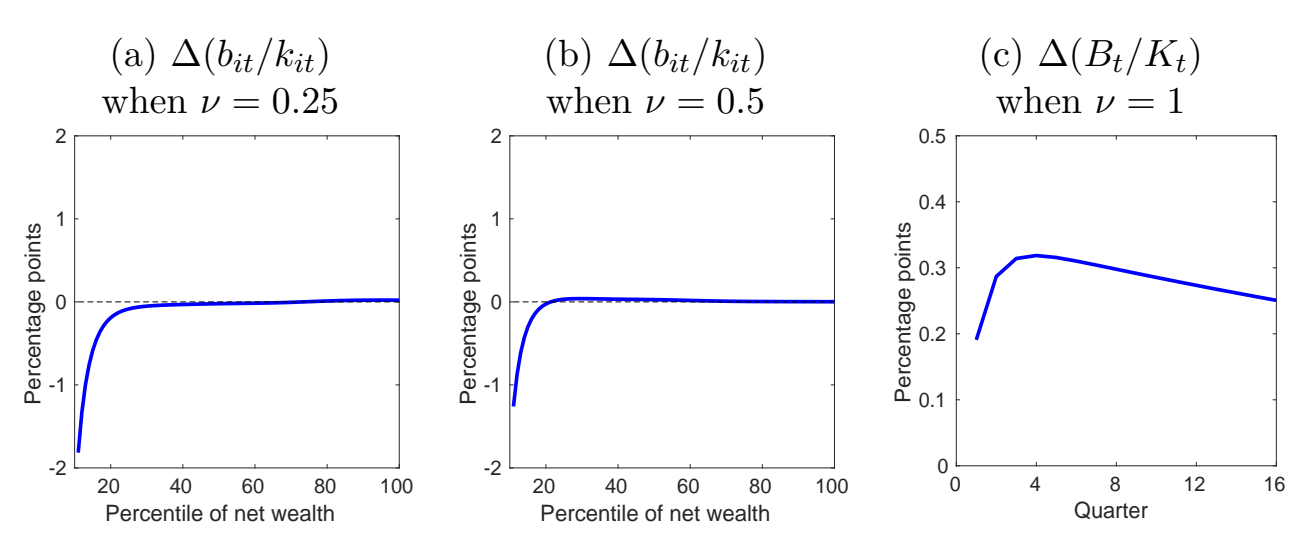

Notes: Panels (a) and (b) show the change in portfolio liquidity after a 1 standard deviation monetary shock, $\epsilon^{R}=36$ basis points (annualized), after 2 years with (a) a $25 \%$ and (b) a $50 \%$ chance of trading capital in a given period. Policies by wealth percentile are estimated using a local linear regression technique with a Gaussian kernel and a bandwidth of 0.1. Panel (c) shows the impulse response function of $B_{t} / K_{t}$ in the case of perfectly liquid capital.

time horizons when more households can adjust their portfolios. In Figure 3. which plots the response of portfolios after 8 quarters, the magnitude of portfolio differences between wealthy and poor households is even more pronounced.

A model with liquid capital, in contrast, implies a counterfactual increase in the portfolio liquidity of all households. Figure 7 shows counterfactuals for three versions of the model: (a) $25 \%$ of households trade capital each period, (b) $50 \%$ of households trade each period, (c) all households trade each period. As capital becomes more liquid, fewer households lower their portfolio liquidity and the magnitude of the portfolio response becomes substantially smaller. When capital and bonds are perfect substitutes, the individual portfolio problem is indeterminate. Aggregate liquidity, $B_{t} / K_{t}$, follows from the arbitrage condition between both assets and the government supply of bonds. Assuming that households hold the average portfolio, portfolio liquidity increases by 0.2 percentage point for all households in the first quarter after the monetary tightening. ${ }^{26}$

\footnotetext{
${ }^{26}$ See Appendix $\mathrm{F} .1$ for more details on the model with liquid capital.
} 


\section{Empirical Evidence}

Monetary policy shocks provide an important validation exercise for macroeconomic models (cf. Ramey, 2016). In this section, I extend this exercise beyond aggregate time series to cross-sectional data on household portfolios to provide evidence for heterogeneity in the response to monetary shocks across households with different wealth.

To that end, I first estimate the effect of monetary policy shocks on aggregate economic activity, average household portfolios from the Flow of Funds, and a measure of the liquidity premium. I then use cross-sectional information on household portfolios from the Survey of Consumer Finances (SCF). I find that wealthy households drive the increase in average liquidity, whereas poorer households see a substantial fall in portfolio liquidity in line with the model.

\subsection{Aggregate Response to Monetary Shocks}

Figure 8 shows the response of aggregate variables to a surprise increase in the federal funds rate. I estimate the responses by local projections with monetary shocks identified by the narrative approach (cf. Romer and Romer, 2004):27

$$
\Upsilon_{t+j}=\beta_{j, 0}+\beta_{j, 1} t+\beta_{j, 2} \bar{\epsilon}_{t}^{R}+\beta_{j, 3} \mathbf{X}_{t-1}+\nu_{t+j}, j=0 \ldots 15
$$

where $\bar{\epsilon}_{t}^{R}$ are monetary shocks with a normalized standard deviation of 1 , $\mathbf{X}_{t}=\left[Y_{t}, C_{t}, I_{t}, R_{t}^{B}, \epsilon_{t}^{R}, \epsilon_{t-1}^{R}\right]$ are aggregate controls and lagged monetary shocks, and $\Upsilon_{t+j}$ is the endogenous variable of interest at horizon $j$. I use quarterly data from 1983 to 2007.28 See Appendix D for more details.

I consider a 1 standard deviation monetary shock (36 basis points annualized) that pushes up the federal funds rate for 3 years. In response, output falls by roughly $0.6 \%$ after 3 years and recovers only slowly. Consumption falls slightly less than output with a similar dynamic. Investment falls too, but its reaction is roughly three times as strong as the output reaction.

The decline in investment finds its reflection in household balance sheets. The ratio of liquid-to-illiquid assets goes up after a monetary tightening;

\footnotetext{
${ }^{27}$ I use the updated shock series by Wieland and Yang $(2016)$.

${ }^{28}$ I focus on the time after the Volcker disinflation and before the Great Recession for two reasons. First, the SCF is only available from 1983 onwards and monetary shocks only up to 2007. Second, this period is less likely to feature structural breaks.
} 
Figure 8: Aggregate response to a monetary shock

Output $Y_{t}$

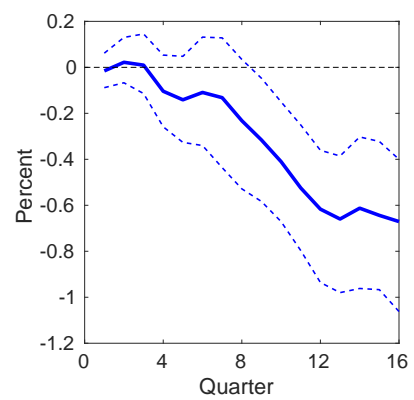

Fed funds rate $R_{t}^{B}$

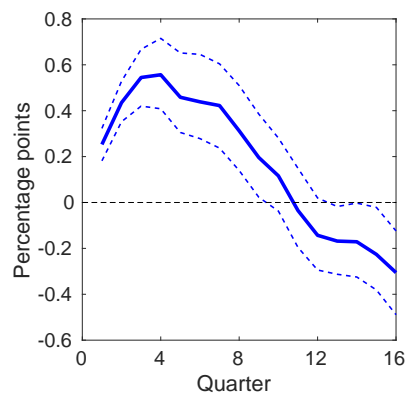

Consumption $C_{t}$

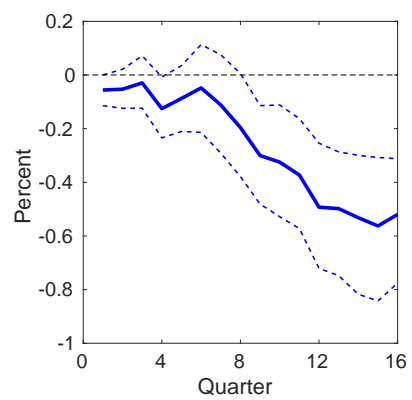

Aggr. liquidity $B_{t} / K_{t}$

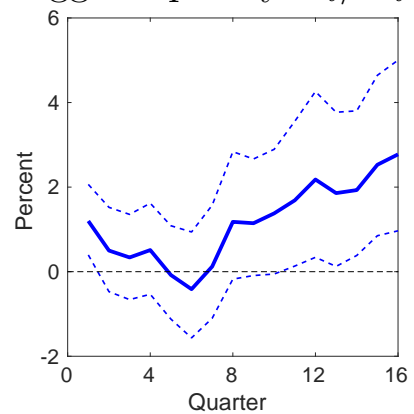

Investment $I_{t}$

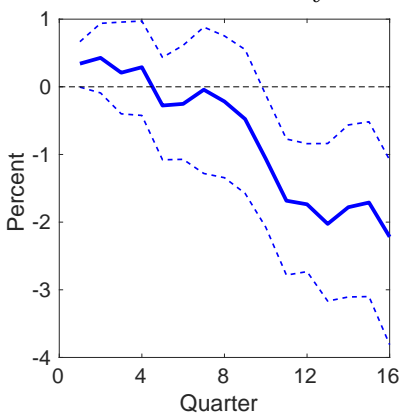

Liquidity premium*

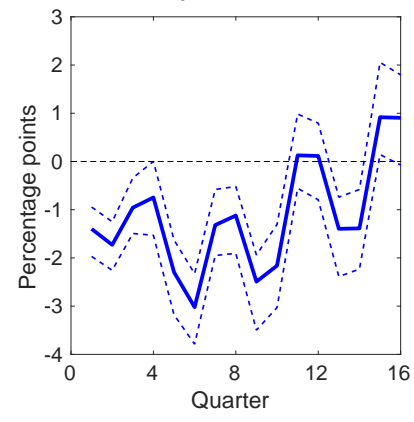

Estimated response of each time series at $t+j, j=1 \ldots 16$ to a monetary policy shock, $\epsilon_{t}^{R}=36$ basis points, where $t$ corresponds to quarters from 1983Q1 to 2007Q4. The regressions control for the lagged state of the economy $\mathbf{X}_{t-1}$, where $\mathbf{X}_{t}=\left[Y_{t}, C_{t}, I_{t}, R_{t}^{B}, \epsilon_{t}^{R}, \epsilon_{t-1}^{R}\right]$. Bootstrapped $90 \%$ confidence bands are shown in the dashed lines (block bootstrap). ${ }^{*}$ Liquidity premium is proxied by realized return on housing (rent-price ratio in $t$ plus realized growth rate of house prices in $t+1)$ relative to the federal funds rate.

see lower middle panel of Figure 8. I calculate this ratio from the Flow of Funds (Table Z1-B.101) by defining liquid assets as all deposits, cash, debt securities (including government bonds), and loans held directly, while I treat all other real and financial assets as illiquid ${ }^{29}$ While average liquidity goes up by around $2 \%$, the liquidity premium falls by 2 percentage points. I proxy the liquidity premium by the realized return on housing (rent-price ratio in $t$ plus realized growth rate of house prices in $t+1$ )

\footnotetext{
${ }^{29}$ Kaplan et al. (2018) adopt a very similar asset taxonomy. The reason to treat equities as illiquid is that most equities are held in the form of pension funds. Equity shares held directly only play a role above the 85 th wealth percentile. Publicly traded equities that a single household can sell without price impact play a significant role in household portfolios only for a relatively small fraction of households and a small fraction of the aggregate capital stock.
} 
relative to the federal funds rate 30

The next section shows that behind the increase in average liquidity lies large heterogeneity in household responses.

\subsection{Household Response to Monetary Shocks}

In the following, I estimate the response of household portfolios to monetary policy shocks. I order households by their net wealth and document heterogeneity in the response of portfolio liquidity across the wealth distribution.

Using the Survey of Consumer Finances, I estimate the liquidity ratio $\frac{\lambda^{L I}(p r c, t)}{\lambda^{I L}(p r c, t)}$ by each percentile, prc, of net wealth for each SCF survey year $t$ from 1983 to 2007. The definition of net liquid wealth corresponds to the Flow of Funds data, i.e., net liquid assets include all savings and checking accounts, call and money market accounts, certificates of deposit, all types of bonds, and private loans net of credit card debt. All other assets are considered illiquid. Appendix C.2 discusses the asset classification and the construction of the liquidity ratios in more detail.

I regress these portfolio measures for each percentile of wealth on annual monetary shocks, $\gamma_{2}\left(\right.$ prc), including an intercept, $\gamma_{0}($ prc $)$, and a linear time trend, $\gamma_{1}(\operatorname{prc})$ :

$$
\lambda^{L I / I L}(p r c, t)=\gamma_{0}(p r c)+\gamma_{1}(p r c) t+\gamma_{2}(p r c) \bar{\epsilon}_{t}^{R}+\zeta,
$$

i.e., I use a local projection technique. Appendix $\mathrm{D}$ spells out the details. Figure 9 reports the coefficients, $\gamma_{2}($ prc $)$, of the portfolio response to monetary shocks. I use a block bootstrap to estimate confidence bands.

Figure 9 reveals large heterogeneity in the response of portfolio liquidity to a surprise increase in the federal funds rate. The liquidity ratio of portfolios held by households in the bottom $40 \%$ in terms of wealth falls by up to 3 percentage points. Only those households in the top of the wealth distribution respond to a higher return on liquid assets by increasing the liquidity of their portfolios. Therefore, wealthy households drive the increase in average liquidity as seen in the Flow of Funds data in Figure 8 ,

Looking at the change of holdings of liquid and illiquid assets separately

\footnotetext{
${ }^{30}$ The house price is the Case-Shiller S\&P national house price index. Rents are imputed on the basis of the CPI for rents of primary residences, fixing the rent-price ratio in $1983 \mathrm{Q} 1$ to $4 \%$.
} 
Figure 9: Portfolio responses to a monetary shock after 2 years

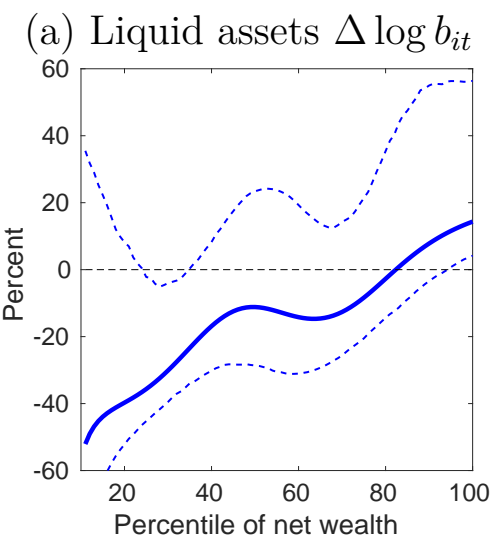

(b) Illiquid assets $\Delta \log k_{i t}$

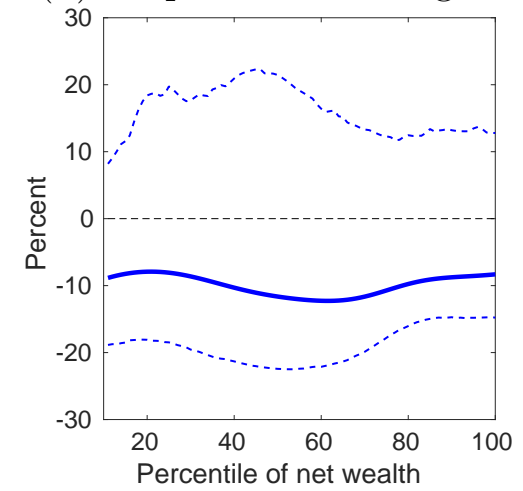

(c) Portfolio liquidity $\Delta\left(b_{i t} / k_{i t}\right)$

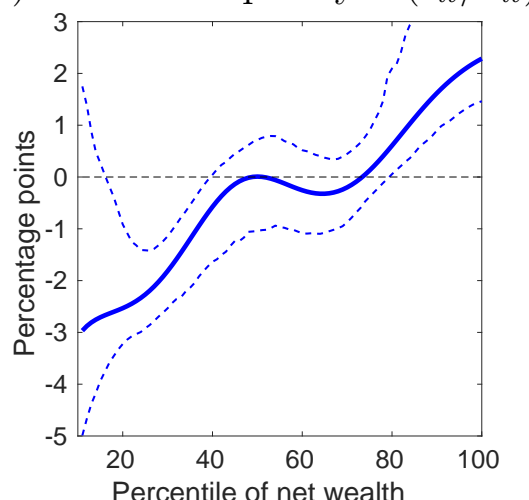

Estimated change in portfolio liquidity after a 1 standard deviation monetary shock, $\epsilon^{R}=36$ basis points (annualized), after 2 years. Portfolio composition is estimated from the SCF years 1983-2007, only households with at least two adults and the household head is between 30 and 55 years of age. Bootstrapped $90 \%$ confidence bands in dashed-lines, based on a non-parametric bootstrap. Plotted from the 11th percentile onwards because poorer households hold negative liquid wealth.

reveals that the sign difference in the portfolio response comes from changes in liquid asset holdings. While most households lower their liquid asset holdings, households in the top $20 \%$ of the wealth distribution save more in liquid assets. In contrast, all households lower their savings in illiquid assets. This is in line with the model.

\section{Conclusion}

The transmission of monetary policy depends on the distribution of marginal propensities to consume (MPC) and invest (MPI). The sum of both propen- 
sities, which is the marginal propensity to spend an additional dollar on goods, matters for aggregate demand, while the propensity to invest matters for the future capital stock. The key to generating realistic heterogeneity in MPCs and MPIs is assets with different degrees of liquidity. Liquidity-constrained households have high MPCs but low MPIs, which makes consumption more and investment less elastic to monetary shocks in comparison to an economy with a representative household.

Redistribution through earnings heterogeneity and the Fisher channel from unexpected inflation is quantitatively important. The latter depends on the covariance between inflation-induced redistribution and the marginal propensities to consume and invest. When the economy is demand-driven, the Fisher channel amplifies the aggregate effects of monetary shocks through heterogeneity in propensities to spend. When prices are flexible, in contrast, the Fisher channel only works through investment and leads to an expansion after a monetary tightening.

These results challenge the conventional view of the monetary transmission mechanism that solely focuses on the intertemporal consumption choice. Quantitatively, equilibrium amplification through income and redistribution explains most of the aggregate effects of monetary policy.

To further assess the importance of heterogeneity in household portfolios, the portfolio problem could be extended in a number of dimensions. So far, the Fisher channel only works through unsecuritized debt in the model. The introduction of collateralized debt should further increase its quantitative importance. Modeling long-term debt goes in the same direction. This also opens a new channel of redistribution through unhedged interest rate exposures; see Auclert (2015).

More generally, it is important to reassess optimal policy in a New Keynesian model with incomplete markets to analyze potential trade-offs between aggregate stabilization and inequality.

\section{References}

Ahn, S., Kaplan, G., Moll, B., Winberry, T., and Wolf, C. (2018). When inequality matters for macro and macro matters for inequality. NBER Macroeconomics Annual, 32(1):1-75. 
Auclert, A. (2015). Monetary policy and the redistribution channel. mimeo, MIT.

Bayer, C., Luetticke, R., Pham-Dao, L., and Tjaden, V. (2015). Precautionary savings, illiquid assets, and the aggregate consequences of shocks to household income risk. CEPR Discussion Paper No. DP10849.

Bi, H., Leeper, E., and Leith, C. (2013). Uncertain fiscal consolidations. Economic Journal, 123(566):31-63.

Bilbiie, F. O. (2008). Limited asset markets participation, monetary policy and (inverted) aggregate demand logic. Journal of Economic Theory, 140(1):162 - 196 .

Broer, T., Hansen, N.-J. H., Krusell, P., and Öberg, E. (2016). The New Keynesian Transmission Mechanism: A Heterogenous-Agent Perspective. NBER Working Paper No. 22418.

Carroll, C. (2006). The method of endogenous gridpoints for solving dynamic stochastic optimization problems. Economics Letters, 91(3):312320 .

Chetty, R., Guren, A., Manoli, D., and Weber, A. (2011). Are micro and macro labor supply elasticities consistent? A review of evidence on the intensive and extensive margins. The American Economic Review, 101(3):471-475.

Christiano, L. J., Eichenbaum, M., and Evans, C. L. (1999). Monetary policy shocks: What have we learned and to what end? Handbook of Macroeconomics, 1:65-148.

Christiano, L. J., Eichenbaum, M., and Evans, C. L. (2005). Nominal rigidities and the dynamic effects of a shock to monetary policy. Journal of Political Economy, 113(1):1-45.

Clarida, R., Gali, J., and Gertler, M. (2000). Monetary policy rules and macroeconomic stability: Evidence and some theory. The Quarterly Journal of Economics, 115(1):147-180.

Cloyne, J., Ferreira, C., and Surico, P. (2016). Monetary policy when households have debt: New evidence on the transmission mechanism. Bank of England Working Paper, 589. 
Coibion, O., Gorodnichenko, Y., Kueng, L., and Silvia, J. (2017). Innocent bystanders? Monetary policy and inequality. Journal of Monetary Economics, 88:70-89.

Den Haan, W. J. (2010). Assessing the accuracy of the aggregate law of motion in models with heterogeneous agents. Journal of Economic Dynamics and Control, 34(1):79-99.

Den Haan, W. J., Rendahl, P., and Riegler, M. (2015). Unemployment (fears) and deflationary spirals. Journal of the European Economic Association.

Fisher, I. (1933). The debt-deflation theory of great depressions. Econometrica, pages 337-357.

Galí, J., López-Salido, J. D., and Vallés, J. (2007). Understanding the effects of government spending on consumption. Journal of the European Economic Association, 5(1):227-270.

Gornemann, N., Kuester, K., and Nakajima, M. (2012). Monetary policy with heterogeneous agents. Philadelphia Fed Working Paper 12-21.

Greenwood, J., Hercowitz, Z., and Huffman, G. W. (1988). Investment, capacity utilization, and the real business cycle. American Economic Review, 78(3):402-417.

Guerrieri, V. and Lorenzoni, G. (2017). Credit crises, precautionary savings, and the liquidity trap. The Quarterly Journal of Economics, 132(3):1427-1467.

Guvenen, F., Kaplan, G., and Song, J. (2014). The glass ceiling and the paper floor: Gender differences among top earners, 1981-2012. NBER Working Paper Series, 20560.

Hagedorn, M. (2018). Prices and inflation when government bonds are net wealth. mimeo, Oslo University.

Hintermaier, T. and Koeniger, W. (2010). The method of endogenous gridpoints with occasionally binding constraints among endogenous variables. Journal of Economic Dynamics and Control, 34(10):2074-2088. 
Johnson, D. S., Parker, J. A., and Souleles, N. S. (2006). Household expenditure and the income tax rebates of 2001. American Economic Review, 96(5):1589-1610.

Jordà, Ò. (2005). Estimation and inference of impulse responses by local projections. American Economic Review, 95(1):161-182.

Kaplan, G., Moll, B., and Violante, G. L. (2018). Monetary policy according to HANK. American Economic Review, 108(3):697-743.

Kaplan, G. and Violante, G. L. (2014). A model of the consumption response to fiscal stimulus payments. Econometrica, 82:1199-1239.

Krusell, P. and Smith, A. A. (1998). Income and wealth heterogeneity in the macroeconomy. Journal of Political Economy, 106(5):867-896.

Kuhn, M. and Ríos-Rull, J.-V. (2013). Update on the US earnings, income and wealth distributional facts: A view from macroeconomic modelers. Federal Reserve Bank of Minneapolis Quarterly Review, 37(1):2016.

McKay, A., Nakamura, E., and Steinsson, J. (2016). The power of forward guidance revisited. The American Economic Review, 106(10):3133-3158.

McKay, A. and Reis, R. (2016). The role of automatic stabilizers in the US business cycle. Econometrica, 84(1):141-194.

Misra, K. and Surico, P. (2014). Consumption, income changes, and heterogeneity: Evidence from two fiscal stimulus programs. American Economic Journal: Macroeconomics, 6(4):84-106.

Oh, H. and Reis, R. (2012). Targeted transfers and the fiscal response to the great recession. Journal of Monetary Economics, 59:S50-S64.

Parker, J. A., Souleles, N. S., Johnson, D. S., and McClelland, R. (2013). Consumer spending and the economic stimulus payments of 2008. American Economic Review, 103(6):2530-53.

Ramey, V. A. (2016). Macroeconomic shocks and their propagation. Handbook of Macroeconomics, 2:71-162.

Ravn, M. O. and Sterk, V. (2017). Job uncertainty and deep recessions. Journal of Monetary Economics, 90:125-141. 
Reiter, M. (2002). Recursive computation of heterogeneous agent models. mimeo, Universitat Pompeu Fabra.

Reiter, M. (2009). Solving heterogeneous-agent models by projection and perturbation. Journal of Economic Dynamics and Control, 33(3):649665 .

Romei, F. (2014). Need for (the right) speed: The timing and composition of public debt deleveraging. mimeo.

Romer, C. D. and Romer, D. H. (2004). A new measure of monetary shocks: Derivation and implications. American Economic Review, 94(4):10551084 .

Rotemberg, J. J. (1982). Sticky prices in the United States. Journal of Political Economy, pages 1187-1211.

Storesletten, K., Telmer, C. I., and Yaron, A. (2004). Cyclical dynamics in idiosyncratic labor market risk. Journal of Political Economy, 112(3):695-717.

Tauchen, G. (1986). Finite state Markov-chain approximations to univariate and vector autoregressions. Economics Letters, 20(2):177 - 181.

Taylor, J. B. (1993). Discretion versus policy rules in practice. In CarnegieRochester Conference Series on Public Policy, volume 39, pages 195-214. Elsevier.

Tobin, J. (1969). A general equilibrium approach to monetary theory. Journal of Money, Credit and Banking, 1(1):15-29.

Walsh, C. E. (2014). Workers, capitalists, wages, and employment. Working Paper Federal Reserve Bank of Richmond.

Werning, I. (2015). Incomplete markets and aggregate demand. NBER Working Paper No. 21448.

Wieland, J. F. and Yang, M.-J. (2016). Financial dampening. NBER Working Paper No. 22141.

Winberry, T. (2016). A toolbox for solving and estimating heterogeneous agent macro models. mimeo, Chicago Booth. 
Wong, A. (2015). Population aging and the transmission of monetary policy to consumption. mimeo, Northwestern.

Woodford, M. (1995). Price-level determinacy without control of a monetary aggregate. Carnegie-Rochester Conference Series on Public Policy, 43(Supplement C):1 - 46. 


\section{A First Order Conditions}

Denote the optimal policies for consumption, bond holdings, and capital holdings as $x_{i}^{*}, b_{i}^{*}, k^{*}, i \in\{a, n\}$ respectively. Let $\mathbf{z}$ be a vector of potential aggregate states. The first-order conditions for an inner solution in the (non-)adjustment case read:

$$
\begin{array}{ll}
k^{*}: \frac{\partial u\left(x_{a}^{*}\right)}{\partial x} q & =\beta E\left[\nu \frac{\partial V_{a}\left(b_{a}^{*}, k^{*} ; \mathbf{z}^{\prime}\right)}{\partial k}+(1-\nu) \frac{\partial V_{n}\left(b_{a}^{*}, k^{*} ; \mathbf{z}^{\prime}\right)}{\partial k}\right] \\
b_{a}^{*}: \frac{\partial u\left(x_{a}^{*}\right)}{\partial x} & =\beta E\left[\nu \frac{\partial V_{a}\left(b_{a}^{*}, k^{*} ; \mathbf{z}^{\prime}\right)}{\partial b}+(1-\nu) \frac{\partial V_{n}\left(b_{a}^{*}, k^{*} ; \mathbf{z}^{\prime}\right)}{\partial b}\right] \\
b_{n}^{*}: \frac{\partial u\left(x_{n}^{*}\right)}{\partial x} & =\beta E\left[\nu \frac{\partial V_{a}\left(b_{n}^{*}, k ; \mathbf{z}^{\prime}\right)}{\partial b}+(1-\nu) \frac{\partial V_{n}\left(b_{n}^{*}, k ; \mathbf{z}^{\prime}\right)}{\partial b}\right]
\end{array}
$$

Note the subtle difference between $(22)$ and $(23)$ that is the different capital stocks $k^{*}$ vs. $k$ in the right-hand side expressions.

Differentiating the value functions with respect to $k$ and $b$, I obtain the following:

$$
\begin{aligned}
\frac{\partial V_{a}(b, k ; \mathbf{z})}{\partial k} & =\frac{\partial u\left[x_{a}^{*}(b, k ; \mathbf{z})\right]}{\partial x}(q(\mathbf{z})+r(\mathbf{z})) \\
\frac{\partial V_{a}(b, k ; \mathbf{z})}{\partial b} & =\frac{\partial u\left[x_{a}^{*}(b, k ; \mathbf{z})\right]}{\partial x} \frac{R^{b}(\mathbf{z})}{\pi(\mathbf{z})} \\
\frac{\partial V_{n}(b, k ; \mathbf{z})}{\partial b} & =\frac{\partial u\left[x_{n}^{*}(b, k ; \mathbf{z})\right]}{\partial x} \frac{R^{b}(\mathbf{z})}{\pi(\mathbf{z})} \\
\frac{\partial V_{n}(b, k ; \mathbf{z})}{\partial k} & =r(\mathbf{z}) \frac{\partial u\left[x_{n}^{*}(b, k ; \mathbf{z})\right]}{\partial x} \\
& +\beta E\left[\nu \frac{\partial V_{a}\left[b_{n}^{*}(b, k ; \mathbf{z}), k ; \mathbf{z}^{\prime}\right]}{\partial k}+(1-\nu) \frac{\partial V_{n}\left[b_{n}^{*}(b, k ; \mathbf{z}), k ; \mathbf{z}^{\prime}\right]}{\partial k}\right] \\
& =r(\mathbf{z}) \frac{\partial u\left[x_{n}^{*}(b, k ; \mathbf{z})\right]}{\partial x}+\beta \nu E \frac{\partial u\left\{x_{a}^{*}\left[b_{n}^{*}(b, k ; \mathbf{z}), k ; \mathbf{z}\right], k ; \mathbf{z}^{\prime}\right\}}{\partial x}\left(q\left(\mathbf{z}^{\prime}\right)+r\left(\mathbf{z}^{\prime}\right)\right) \\
& +\beta(1-\nu) E \frac{\partial V_{n}\left\{\left[b_{n}^{*}(b, k ; \mathbf{z}), k ; \mathbf{z}\right], k ; \mathbf{z}^{\prime}\right\}}{\partial k}
\end{aligned}
$$

The marginal value of capital in the case of non-adjustment is defined recursively.

Substituting the second set of equations into the first set of equations, 
I obtain the following Euler equations (in slightly shortened notation):

$$
\begin{gathered}
\frac{\partial u\left[x_{a}^{*}(b, k ; \mathbf{z})\right]}{\partial x} q(\mathbf{z})=\beta E\left[\nu \frac{\partial u\left[x_{a}^{*}\left(b_{a}^{*}, k^{*} ; \mathbf{z}^{\prime}\right)\right]}{\partial x}\left[q\left(\mathbf{z}^{\prime}\right)+r\left(\mathbf{z}^{\prime}\right)\right]+(1-\nu) \frac{\partial V^{n}\left(b_{a}^{*}, k^{*} ; \mathbf{z}^{\prime}\right)}{\partial k}\right] \\
\frac{\partial u\left[x_{a}^{*}(b, k ; \mathbf{z})\right]}{\partial x}=\beta E \frac{R^{b}\left(\mathbf{z}^{\prime}\right)}{\pi\left(\mathbf{z}^{\prime}\right)}\left[\nu \frac{\partial u\left[x_{a}^{*}\left(b_{a}^{*}, k^{*} ; \mathbf{z}^{\prime}\right)\right]}{\partial x}+(1-\nu) \frac{\partial u\left[x_{n}^{*}\left(b_{a}^{*}, k^{*} ; \mathbf{z}^{\prime}\right)\right]}{\partial x}\right] \\
\frac{\partial u\left[x_{n}^{*}(b, k, ; \mathbf{z})\right]}{\partial x}=\beta E \frac{R^{b}\left(\mathbf{z}^{\prime}\right)}{\pi\left(\mathbf{z}^{\prime}\right)}\left[\nu \frac{\partial u\left[x_{a}^{*}\left(b_{n}^{*}, k ; \mathbf{z}^{\prime}\right)\right]}{\partial x}+(1-\nu) \frac{\partial u\left[x_{n}^{*}\left(b_{n}^{*}, k ; \mathbf{z}^{\prime}\right)\right]}{\partial x}\right]
\end{gathered}
$$

In words, the optimal portfolio allocation compares the one-period return difference between the two assets for the case of adjustment and nonadjustment, taking into account the adjustment probability. In case of adjustment, the return difference is $E \frac{R^{b}\left(z^{\prime}\right)}{\pi\left(z^{\prime}\right)}-E \frac{r\left(z^{\prime}\right)+q\left(z^{\prime}\right)}{q(z)}$ weighted with the marginal utility under adjustment. In case of non-adjustment, the return difference becomes $E \frac{R^{b}\left(z^{\prime}\right)}{\pi\left(z^{\prime}\right)} \frac{\partial u\left[x_{n}^{*}\left(b_{a}^{*}, k^{\prime} ; z^{\prime}\right)\right]}{\partial x}-\frac{\partial V^{n}\left(b_{a}^{*}, k^{\prime} ; z^{\prime}\right)}{\partial k^{\prime}}$, where the latter part is the marginal value of illiquid assets when not adjusting. The latter reflects both the utility derived from the dividend stream and the utility from occasionally selling the asset.

\section{For Online Publication}

\section{B Numerical Solution}

My model has a three-dimensional idiosyncratic state space with two endogenous states. This renders solving the model by perturbing the histogram and the value functions on a full grid infeasible such that I cannot apply a perturbation method without state-space reduction as done in Reiter (2002).

Instead, I apply a method developed in joint-work with Christian Bayer. Bayer et al. (2015) propose a variant of Reiter's (2009) method to solve heterogeneous agent models with aggregate risk. The key to reducing the dimensionality of the system is Sklar's Theorem. I write the distribution function in its copula form: $\Theta_{t}=\mathcal{C}_{t}\left(F_{t}^{b}, F_{t}^{k}, F_{t}^{h}\right)$ with the copula $\mathcal{C}_{t}$ and the marginal distributions for liquid and illiquid assets and productivity $F_{t}^{b, k, h}$. Assuming $\mathcal{C}_{t}=\mathcal{C}$ breaks the curse of dimensionality because one only needs 
to perturb the marginal distributions.

The idea behind this approach is that given the economic structure of the model, prices only depend on aggregate asset demand and supply, as in Krusell and Smith (1998), and not directly on higher moments of the joint distributions $\Theta_{t}, \Theta_{t+1}$. Fixing the copula to its steady state imposes no restriction on how the marginal distributions change, i.e., how many more or less liquid assets the portfolios of the x-th percentile have. It only restricts the change in the likelihood of a household being among the $\mathrm{x}$ percent richest in liquid assets to be among the y-percent richest in illiquid assets.

For the policies, I use a sparse polynomial $P(b, k, h)$ with parameters $\Xi_{t}=\Xi\left(R_{t}^{B}, \Theta_{t}, \epsilon_{t}^{R}\right)$ to approximate the value functions at all grid points around their value in the stationary equilibrium without aggregate risk, $V^{S S}(b, k, h)$. For example, I write the value function as

$$
V\left(b, k, h ; R_{t}^{B}, \Theta_{t}, \epsilon_{t}^{R}\right) / V^{S S}(b, k, h) \approx P(b, k, h) \Xi_{t} .
$$

Note the difference to a global approximation of the value function for finding the stationary equilibrium without aggregate risk. Here, I only use the sparse polynomial to capture deviations from the stationary equilibrium values, cf. Ahn et al. (2018) and different from Winberry (2016) and Reiter (2009). I define the polynomial basis functions such that the grid points of the full grid coincide with the Chebyshev nodes for this basis.

The economic model boils down to a dynamic system that can be represented by a set of non-linear difference equations, for which hold

$$
E_{t} F\left(X_{t}, X_{t+1}, Y_{t}, Y_{t+1}\right)=0
$$

where the set of control variables is $Y_{t}=\left(\frac{\partial V_{t}}{\partial b}, \frac{\partial V_{t}}{\partial k}, \tilde{Y}_{t}\right)$, i.e., derivatives of the value function with respect to $b$ and $k$ as well as some aggregate controls $\tilde{Y}_{t}$ such as dividends, wages, etc. The set of state variables $X_{t}=\left(\Theta_{t}, R_{t}^{B}, \epsilon_{t}^{R}\right)$ is given by the histogram $\Theta_{t}$ of the distribution over $(b, k, h)$ and the aggregate states $R_{t}^{B}$ and $\epsilon_{t}^{R}$.

Finally, I check the quality of the linearized solution (in aggregate shocks) by solving the household planning problem given the implied expected continuation values from the approximate solution but solving for the actual intratemporal equilibrium, as suggested by Den Haan (2010). 
Table 4: Den Haan (2010) statistic

\begin{tabular}{lcccc}
\hline \hline \multicolumn{5}{c}{ Absolute error (in \%) for } \\
& Price of Capital $q_{t}$ & Capital $K_{t}$ & Inflation $\pi_{t}$ & Real Bonds $B_{t}$ \\
\hline Mean & 0.03 & 0.30 & 0.06 & 0.76 \\
Max & 0.06 & 0.72 & 0.19 & 2.24 \\
& & \\
\hline Notes: Differences in percent between the simulation of the linearized solution \\
of the model with monetary shocks and a simulation in which I solve for \\
the actual intratemporal equilibrium prices in every period given the implied \\
expected continuation values for $t=\{1, \ldots, 250\} ;$ see Den Haan (2010).
\end{tabular}

I simulate the economy over $\mathrm{T}=250$ periods and calculate the differences between the linearized solution and the non-linear one. The maximum difference is $0.72 \%$ for the capital stock and $2.24 \%$ for bonds while the mean absolute errors are substantially smaller; see Table 4 . Absolute errors for equilibrium bond supply are the largest because of the high autocorrelation in bonds supply $\left(\rho_{B}=0.98\right)$. With balanced budget rule, $\rho_{B}=0.0$, the absolute errors are smaller than $1 \%$.

\section{Description of Aggregate and Cross-Sectional Data}

\section{C.1 Data from the Flow of Funds}

The financial accounts of the Flow of Funds (FoF), Table Z1, report the aggregate balance sheet of the U.S. household sector (including nonprofit organizations serving households). I use this data in my analysis to measure changes in the aggregate ratio of net liquid to net illiquid assets on a quarterly basis. The asset taxonomy is the following and closely corresponds to my definition of liquidity in the cross-sectional data.

Net liquid assets are defined as total currency and deposits, money market fund shares, various types of debt securities (Treasury, agency- and GSE-backed, municipal, corporate and foreign), loans (as assets), and total miscellaneous assets net of consumer credit, depository institution loans n.e.c., and other loans and advances.

Net illiquid wealth includes real estate at market value, life insur- 
ance reserves, pension entitlements, equipment and non-residential intellectual property products of non-profit organizations, proprietors' equity in non-corporate business, corporate equities, mutual fund shares subtracting home mortgages as well as commercial mortgages.

\section{C.2 Data from the Survey of Consumer Finances}

I use nine waves of the Survey of Consumer Finances (SCF, 1983-2007) for the empirical analysis of the response of household portfolios to monetary shocks and for the calibration of the model. I restrict the sample to households with two married adults whose head is between 30 and 55 years of age to control for changing demographics and exclude education and retirement decisions that are not explicitly modeled. The asset taxonomy is the following.

Net liquid assets include all households' savings and checking accounts, call and money market accounts (incl. money market funds), certificates of deposit, all types of bonds (such as savings bonds, U.S. government bonds, Treasury bills, mortgage-backed bonds, municipal bonds, corporate bonds, foreign and other tax-free bonds), and private loans net of credit card debt.

All other assets are considered illiquid. Most households hold their illiquid wealth in real estate and pension wealth from retirement accounts and life insurance policies. Furthermore, I treat business assets, other nonfinancial and managed assets and corporate equity in the form of directly held mutual funds and stocks as illiquid, because a large share of equities owned by private households is not publicly traded nor widely circulated (see Kaplan et al., 2018). From gross illiquid asset holdings, I subtract all debt except for credit card debt.

I exclude cars and car debt from the analysis altogether. What is more, I exclude from the analysis households that hold massive amounts of credit card debt such that their net liquid assets are below minus half of the average quarterly household income - the debt limit I use in the model. Moreover, I exclude all households with negative equity in illiquid assets. This excludes roughly $5 \%$ of U.S. households on average from the analysis. Figure 10 and Table 5 display some key statistics of the distribution of liquid and illiquid assets in the population and the model.

I estimate the asset holdings at each percentile of the net wealth distribution by running a local linear regression that maps the percentile rank 
Figure 10: Average portfolio liquidity by liquid/net wealth quintiles

(a) Model

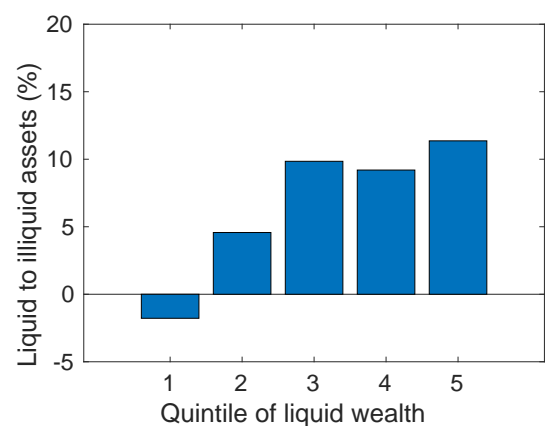

(c) Model

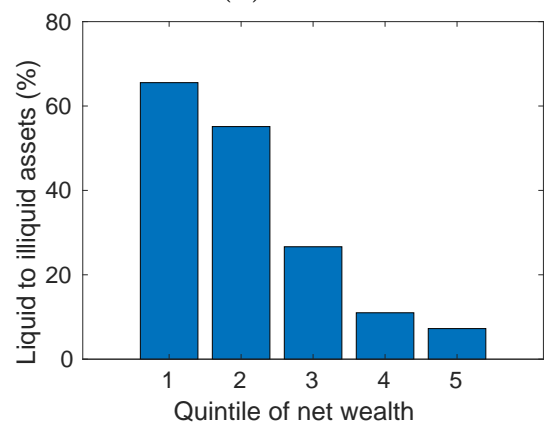

(b) Data

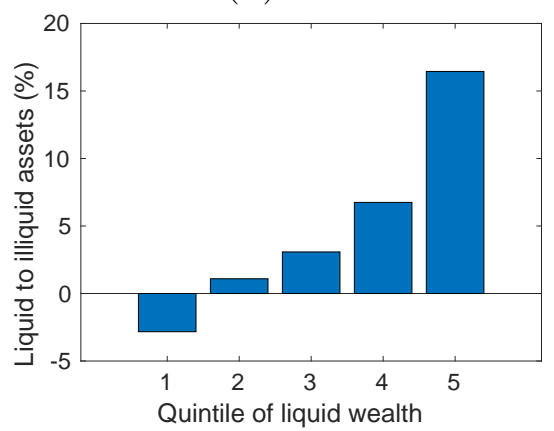

(d) Data

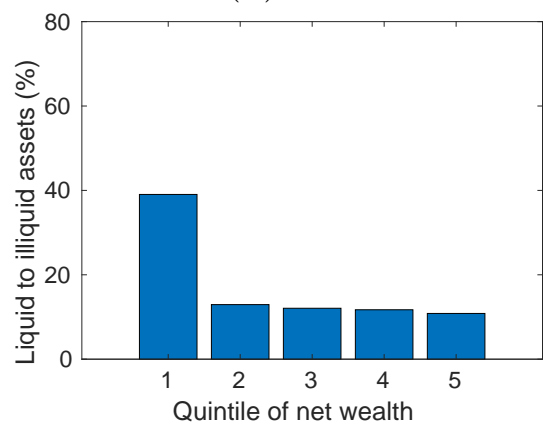

Notes: Panels (a) and (b): Estimated net liquid asset holdings relative to estimated net illiquid assets by quintile of the liquid wealth distribution. Panels (c) and (d): Estimated positive liquid asset holdings relative to estimated net illiquid assets by quintile of the net wealth distribution.

Average over the estimates from the SCFs 1983-2007 (for households composed of at least two adults whose head is between 30 and 55 years of age). Estimation by a local linear estimator with a Gaussian kernel and a bandwidth of 0.1 . 
in net wealth into the net liquid and net illiquid asset holdings. In detail, let $L I_{i t}$ and $I L_{i t}$ be the value of liquid and illiquid assets of household $i$ in the SCF of year $t$, respectively. Let $\omega_{i t}$ be its sample weight. Then I first sort households by net wealth $\left(L I_{t}+I L_{t}\right)$ and calculate the percentile rank of a household $i$ as $\operatorname{prc}_{i t}=\sum_{j<i} \omega_{j t} / \sum_{j} \omega_{j t}$. I then run for each percentile, $\operatorname{prc}=0.01,0.02, \ldots 1$, a local linear regression. For this regression, I calculate the weight of household $i$ as $w_{i t}=\sqrt{\phi\left(\frac{\mathbf{p r c}_{i t}-p r c}{h}\right) \omega_{i t}}$, where $\phi$ is the probability density function of a standard normal, and $h=0.1$ is the bandwidth. I then estimate the liquid and illiquid asset holdings at percentile prc at time $t$ as the intercepts $\lambda^{L I, I L}(\operatorname{prc}, t)$ obtained from the weighted regressions for year $t$ :

$$
\begin{aligned}
& w_{i t} L I_{i t}=\lambda^{L I}(\operatorname{prc}, t) w_{i t}+\beta^{L I}(\operatorname{prc}, t)\left(\operatorname{prc}_{i t}-\operatorname{prc}\right) w_{i t}+\zeta_{i t}^{L I}, \\
& w_{i t} I L_{i t}=\lambda^{I L}(\operatorname{prc}, t) w_{i t}+\beta^{I L}(\operatorname{prc}, t)\left(\operatorname{prc}_{i t}-p r c\right) w_{i t}+\zeta_{i t}^{I L},
\end{aligned}
$$

where $\zeta^{L I / I L}$ are error terms.

Figure 11 compares the percentage deviations of average portfolio liquidity, $\sum_{p r c} \lambda^{L I}(p r c, t) / \sum_{p r c} \lambda^{I L}(p r c, t)$, from their long-run mean to those obtained from the FoF data for the years 1983 to 2007. Both data sources capture very similar changes in the liquidity ratio over time.

The average liquid to illiquid assets ratios, however, differ between the SCF and FoF. The SCF systematically underestimates gross financial assets and, hence, liquid asset holdings. The liquidity ratio in the FoF is roughly $20 \%$, about twice as large as the one in the SCF. One reason is that households are more likely to underestimate their deposits and bonds due to a large number of potential asset items, whereas they tend to overestimate the value of their real estate and equity (compare also Table C.1. in Kaplan et al. 2018). 
Table 5: Household portfolio composition:

Survey of Consumer Finances 1983-2007

Married households with head between 30 and 55 years of age

\begin{tabular}{lcc}
\hline \hline Moments & Model & Data \\
\hline Fraction with $b<0$ & 0.16 & 0.16 \\
Fraction with $k>0$ & 0.88 & 0.91 \\
Fraction with $b \leq 0$ and $k>0$ & 0.11 & 0.13 \\
Gini liquid wealth & 0.80 & 0.88 \\
Gini illiquid wealth & 0.78 & 0.78 \\
Gini total wealth & 0.78 & 0.78 \\
\hline
\end{tabular}

Notes: Averages over the SCFs 1983-2007 using the respective crosssectional sampling weights. Households whose liquid asset holdings fall below minus half of the average quarterly income are dropped from the sample. Ratios of liquid to illiquid wealth are estimated by first estimating local linear functions that map the percentile of the wealth distribution into average liquid and average illiquid asset holdings for each year, then averaging over years and finally calculating the ratios.

Figure 11: Deviation of portfolio liquidity from mean in SCF and FoF

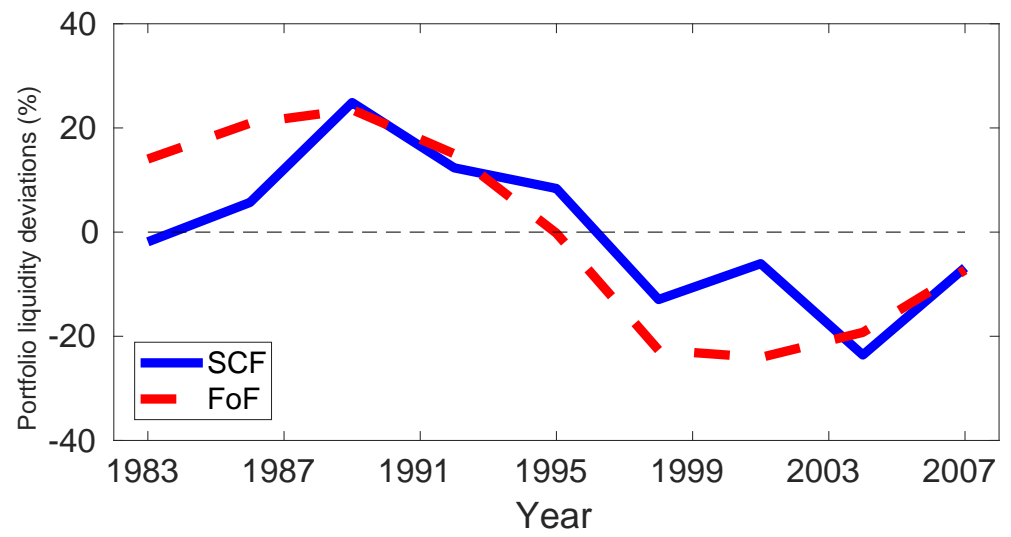




\section{C.3 Other Aggregate Data}

Section 5 shows the impulse response functions of the log of real GDP, real personal consumption expenditures, and real gross private investment. These variables are taken from the national accounts data provided by the Federal Reserve Bank of St. Louis (Series: PCEC, GPDI). GDP is calculated as the sum of real consumption, real investment, and real government purchases (GCEC1).

Data on the federal funds rate and the liquidity premium come from the same source. I construct the liquidity premium from nominal house prices, the CPI for rents, and the federal funds rate. House prices come from the Case-Shiller S\&P U.S. National Home Price Index (CSUSHPINSA) divided by the all-items CPI (CPIAUCSL). I measure the liquidity premium as the excess realized return on housing. This is composed of the rent-price-ratio, $R_{h, t}$, in $t$ plus the quarterly growth rate of house prices in $t+1, \frac{H_{t+1}}{H_{t}}$, over the nominal rate, $R_{t}^{B}$, (converted to a quarterly rate):

$$
L P_{t}=\frac{R_{h, t}}{H_{t}}+\frac{H_{t+1}}{H_{t}}-\left(1+R_{t}^{B}\right)^{\frac{1}{4}}
$$

Rents are imputed on the basis of the CPI for rents on primary residences paid by all urban consumers (CUSR0000SEHA) fixing the rent-price-ratio in $1983 \mathrm{Q} 1$ to $4 \%$.

\section{Details on the Empirical Estimates of the Response to Monetary Shocks}

\section{D.1 Local Projection Method for Aggregate Data}

Figure 8 of Section 5 shows impulse response functions based on local projections (see Jordà, 2005). This method does not require the specification and estimation of a vector autoregressive model for the true data generating process. Instead, in the spirit of multi-step direct forecasting, the impulse responses of the endogenous variables $\Upsilon$ at time $t+j$ to monetary shocks, $\epsilon_{t}^{R}$, at time $t$ are estimated using horizon-specific single regressions, in which the endogenous variable shifted ahead is regressed on the current normalized monetary shock $\bar{\epsilon}_{t}^{R}$ (with standard deviation 1), a constant, a time trend, and controls $\mathbf{X}_{t-1}$. These controls are specified as the lagged 
federal funds rate $R_{t-1}^{B}$ and the $\log$ of GDP $Y_{t-1}$, consumption $C_{t-1}$, investment $I_{t-1}$, and of lagged monetary shocks $\epsilon_{t-1}^{R}, \epsilon_{t-2}^{R}$ :

$$
\Upsilon_{t+j}=\beta_{j, 0}+\beta_{j, 1} t+\beta_{j, 2} \bar{\epsilon}_{t}^{R}+\beta_{j, 3} \mathbf{X}_{t-1}+\nu_{t+j}, j=0 \ldots 15
$$

Hence, the impulse response function $\beta_{j, 0}$ is just a sequence of projections of $\Upsilon_{t+j}$ in response to the shock $\bar{\epsilon}_{t}^{R}$, local to each forecast horizon $j=0 \ldots 15$. I focus on the post-Volcker disinflation era and use aggregate time series data from 1983Q1 to 2007Q4.

An important assumption made for employing the local projection method, which directly regresses the shocks on the endogenous variable of interest, is that the identified monetary shocks $\epsilon_{t}^{R}$ obtained from narrative approach are exogenous. To this end, I use monetary shocks identified by Wieland and Yang (2016) that improve on the original shock series by Romer and Romer (2004).

\section{E Distributional Consequences: Gini Indexes}

Figure 12: Response of inequality to a monetary shock

(a) Gini Wealth

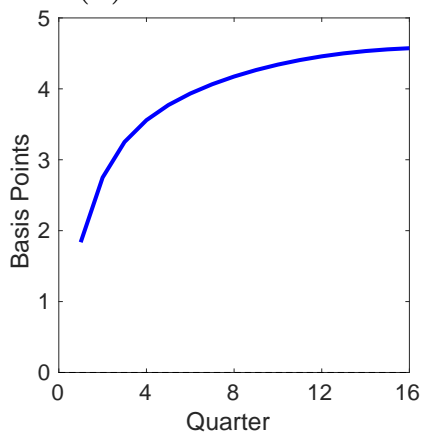

(b) Gini Income

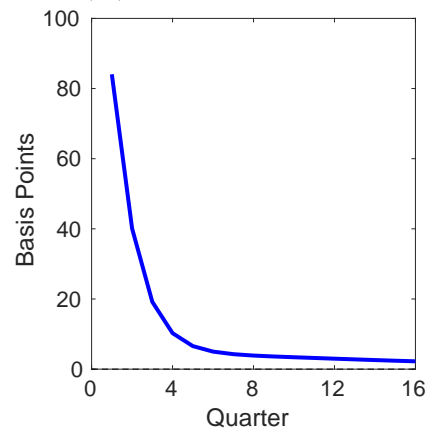

(c) Gini Consumption

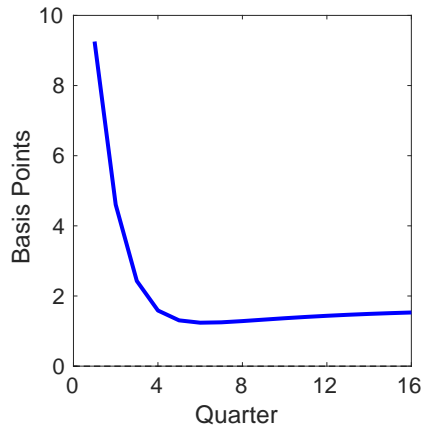

Notes: Impulse responses of Gini indexes of wealth, income, and consumption to an 36 basis points (annualized) monetary policy shock, $\epsilon^{R}$. The y-axis shows basis point changes (an increase of "100" implies an increase in the Gini index from, say, 0.78 to 0.79$)$.

Figure 12 displays the Gini indexes for total wealth, income, and consumption. Inequality in income and consumption instantaneously react to the contractionary monetary policy shock, whereas wealth inequality slowly 
builds up. The initial increase in the Gini index for income is almost 10 times larger than the increase in the Gini index for consumption. This implies substantial consumption smoothing. The dynamics of income inequality follow the response of inflation, which quickly returns to its steady state value and with it profits as well. The increase in consumption inequality, in contrast, is more persistent because of a prolonged time of higher wealth inequality.

\section{F Model Extensions}

\section{F.1 Model without liquidity friction}

To highlight the importance of the liquidity friction, I solve a version of the model in which both assets are liquid. In this case, the household portfolio position between the two assets is indeterminate in the steady state as long as the expected returns of both assets are equal

$$
E_{t}\left[r_{t+1}+\frac{q_{t+1}}{q_{t}}\right]=E_{t}\left[\frac{R_{t+1}^{b}}{\pi_{t+1}}\right],
$$

and in equilibrium they must be equal for households to be willing to hold a positive amount of both assets.

Since the solution method linearizes the problem in the presence of aggregate shocks, the portfolio problem remains indeterminate. Therefore, I assume that all households hold the same bond-to-capital ratio, which is in the aggregate determined by (35) and by the supply of government bonds.

Figure 13 plots the aggregate effects of a monetary tightening in this environment. Output falls by $13 \%$ more relative to the baseline economy with heterogeneity in portfolios because the fall of investment is substantially stronger. The investment response is now only $10 \%$ smaller than with complete markets. Heterogeneity in the response of household portfolios therefore explains most of the decline in the elasticity of investment to monetary shocks. Aggregate liquidity, $B_{t} / K_{t}$, increases and so does individual portfolio liquidity by assumption in the case of liquid capital. Additionally, the (ex-post) liquidity premium increases, which is counterfactual; compare to Figure 8.

Aggregate capital adjustment costs are no substitute for heterogene- 
Figure 13: Aggregate response to a monetary shock with liquid capital
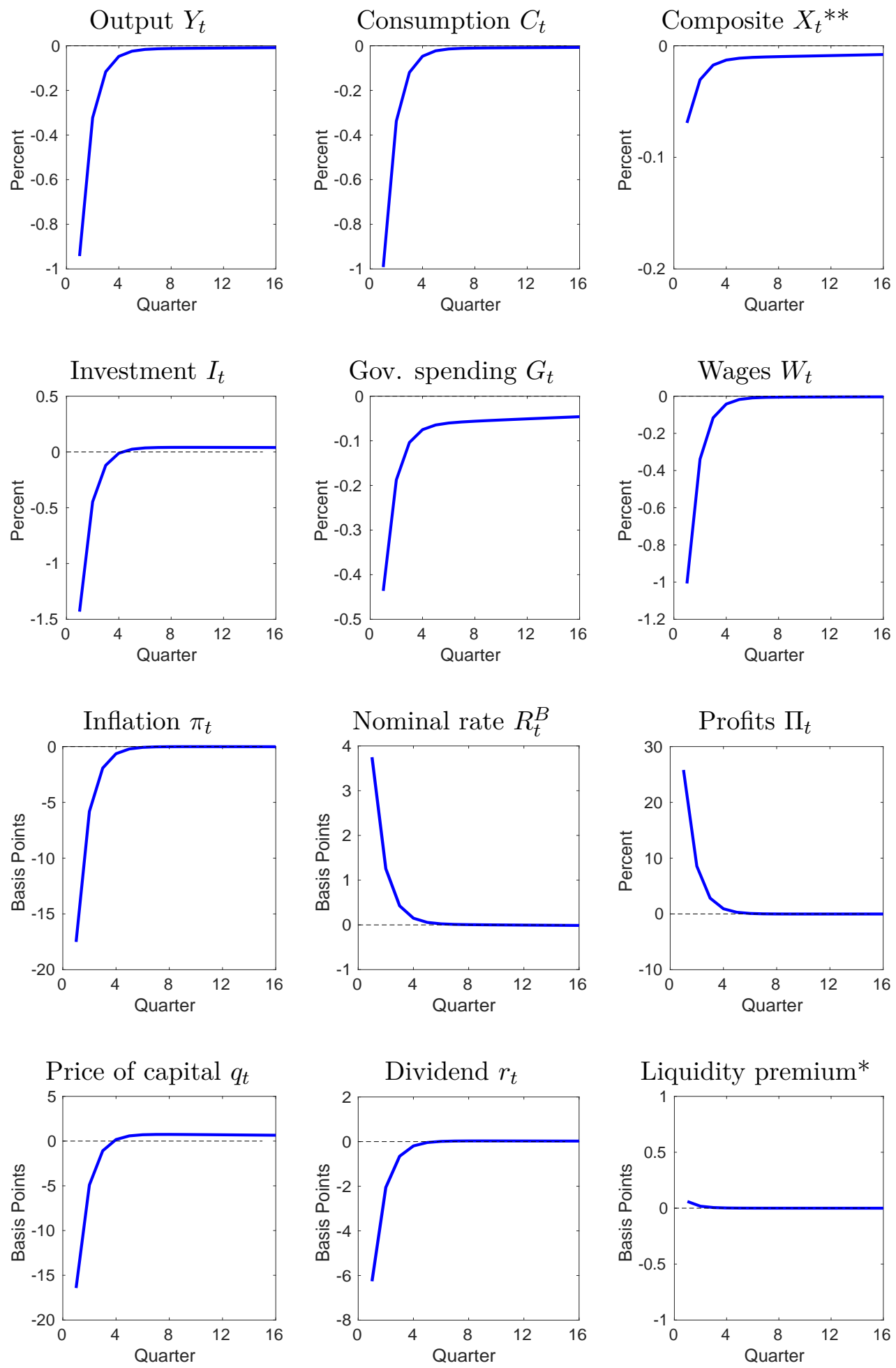

Liquidity premium*

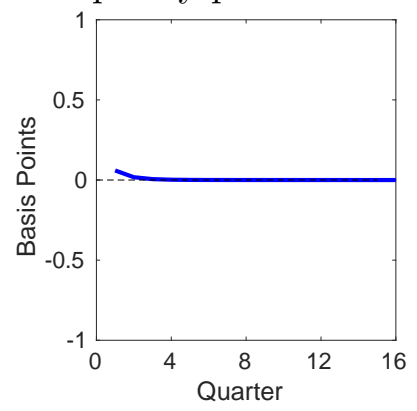

Notes: Impulse responses to a 1 standard deviation monetary policy shock, $\epsilon^{R}=36$ basis points (annualized). All rates (dividends, interest, liquidity premium) are not annualized. ${ }^{*} L P=\frac{E_{t} q_{t+1}+r_{t}}{q_{t}}-\frac{R_{t}^{B}}{E_{t} \pi_{t+1}} * * X_{t}=\int\left(c_{i t}-h_{i t} \frac{n_{i t}^{1+\gamma}}{1+\gamma}\right) d i$ 
Figure 14: Aggregate response to a monetary shock with liquid capital and recalibrated aggregate capital adjustment costs
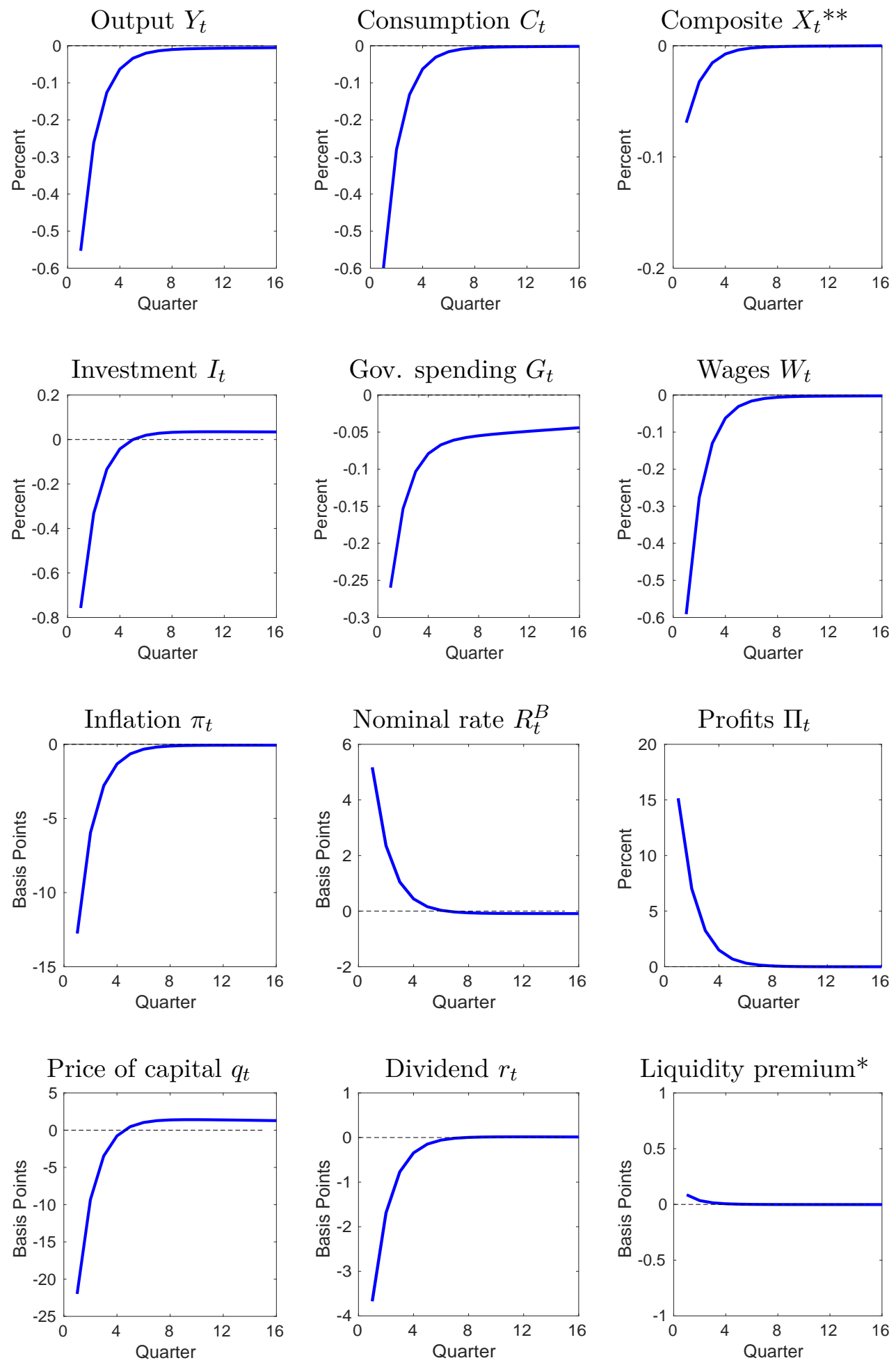

Notes: Impulse responses to a 1 standard deviation monetary policy shock, $\epsilon^{R}=36$ basis points (annualized). All rates (dividends, interest, liquidity premium) are not annualized. ${ }^{*} L P=\frac{E_{t} q_{t+1}+r_{t}}{q_{t}}-\frac{R_{t}^{B}}{E_{t} \pi_{t+1}} * * X_{t}=\int\left(c_{i t}-h_{i t} \frac{n_{i t}^{1+\gamma}}{1+\gamma}\right) d i$ 
ity in household portfolios. Figure 14 shows the impulse responses of an economy with liquid capital but with recalibrated adjustment costs parameter, $\phi$, such that investment falls exactly as in the baseline. In this case, consumption and output fall by around $40 \%$ less as well. Aggregate capital adjustment costs mainly rescale the aggregate effects of monetary policy, but do not affect the composition of the output drop in terms of consumption and investment to the extent that heterogeneity in household portfolios does.

\section{F.2 Model without aggregate capital adjustment costs}

Figure 16 plots the aggregate effects of a monetary tightening in the baseline model without aggregate capital adjustment costs, $\phi=0$. The aggregate effects become more pronounced because investment falls more, while the price of capital is now constant. Overall, the results are very similar to the baseline. The fall in portfolio liquidity in the cross-section is also slightly stronger; see Figure 15.

When markets are complete, investment falls by $4.7 \%$ on impact without aggregate capital adjustment costs. Therefore, the difference to the model with incomplete markets becomes substantially larger when aggregate adjustment costs approach zero.

Figure 15: Portfolio response without aggregate capital adjustment costs

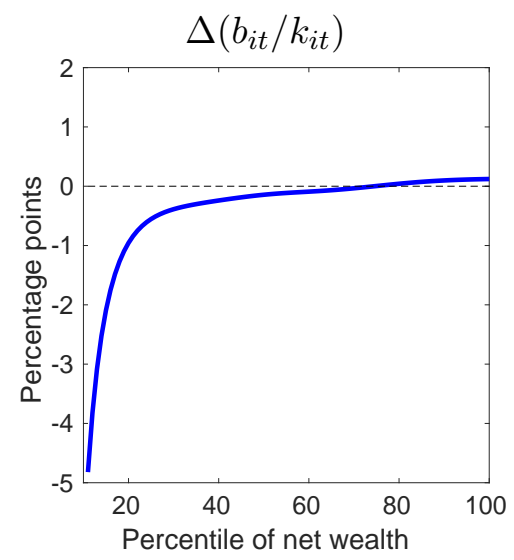

Notes: Change in portfolio liquidity after a 1 standard deviation monetary shock, $\epsilon^{R}=36$ basis points (annualized), after 2 years. Policies by wealth percentile are estimated using a local linear regression technique with a Gaussian kernel and a bandwidth of 0.1 . Plotted from the 11th percentile onwards because poorer households hold negative liquid wealth. 
Figure 16: Aggregate response to a monetary shock without aggregate capital adjustment costs
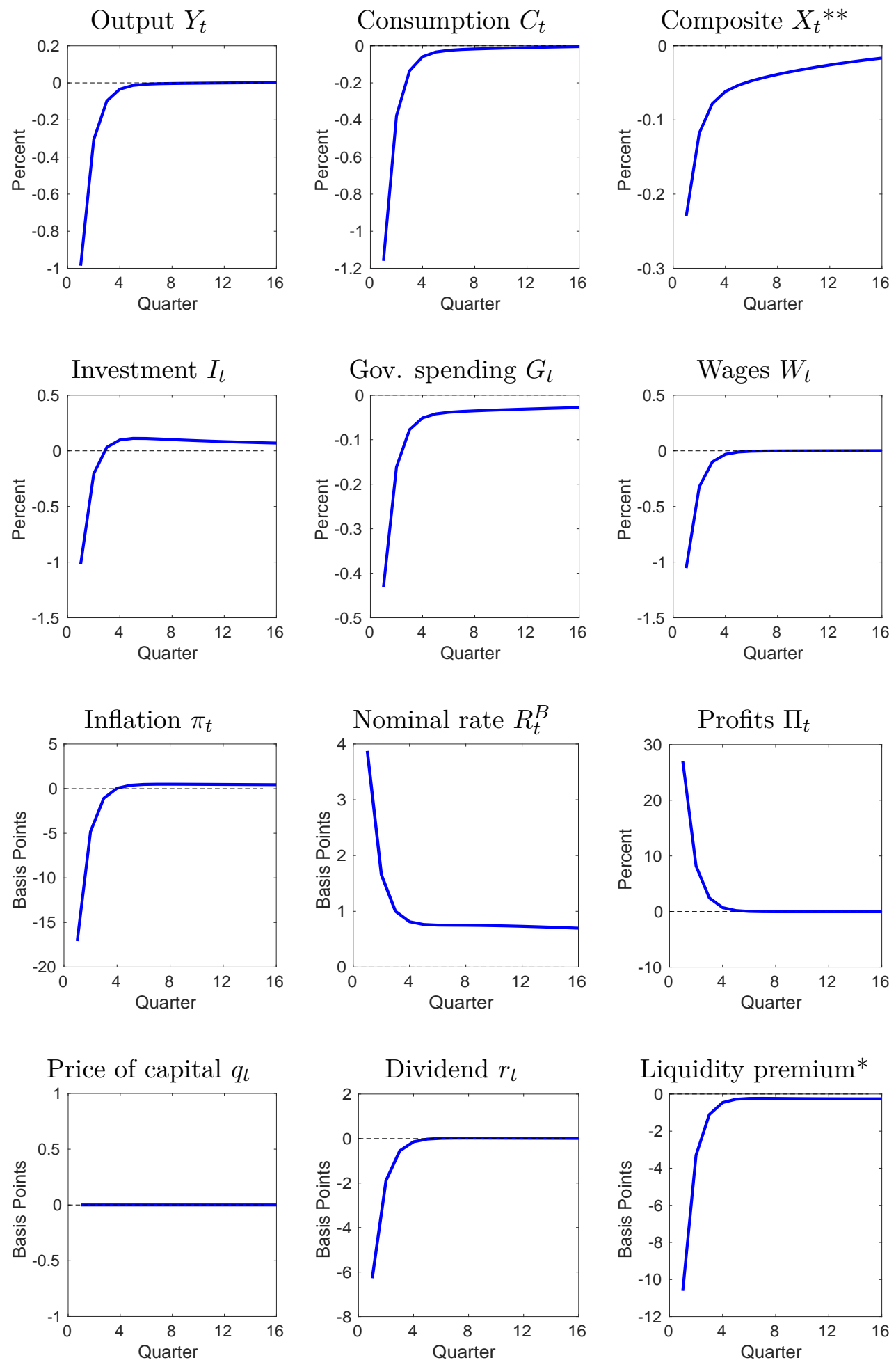

Notes: Impulse responses to a 1 standard deviation monetary policy shock, $\epsilon^{R}=36$ basis points (annualized). All rates (dividends, interest, liquidity premium) are not annualized. ${ }^{*} L P=\frac{E_{t} q_{t+1}+r_{t}}{q_{t}}-\frac{R_{t}^{B}}{E_{t} \pi_{t+1}} * * X_{t}=\int\left(c_{i t}-h_{i t} \frac{n_{i t}^{1+\gamma}}{1+\gamma}\right) d i$ 


\section{F.3 Allocation of profits}

In the baseline model the allocation of profits follows a simple and transparent rule that allocates profits to a random and small fraction of households. These households have zero productivity in the labor market but earn roughly 15 times more than the average worker. This mimics the U.S. distribution of income in terms of inequality and composition of income. According to the Congressional Budget Office, the top $1 \%$ of the income distribution receives about $30 \%$ of their income from financial income, a much larger share than any other segment of the population.

A lump-sum allocation of profits, in contrast, does not match these facts. It further makes earnings-risk procyclical in the model, which mitigates the aggregate effects of monetary policy shocks. Figure 18 plots the impulse responses for the model with lump-sum allocation of profits and without the 'entrepreneur' state (no parameters are recalibrated). The model still generates a sign difference in the portfolio response for wealthy and poor households, but the magnitude of the portfolio response is smaller; See Figure 17.

Figure 17: Portfolio response with lump-sum profits

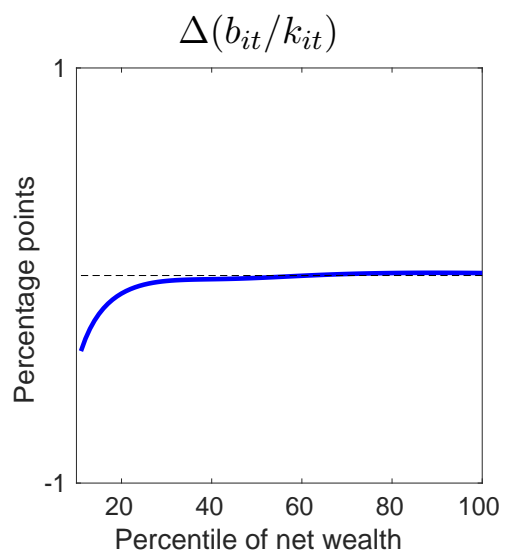

Notes: Change in portfolio liquidity after a 1 standard deviation monetary shock, $\epsilon^{R}=36$ basis points (annualized), after 2 years. Policies by wealth percentile are estimated using a local linear regression technique with a Gaussian kernel and a bandwidth of 0.1. Plotted from the 11th percentile onwards because poorer households hold negative liquid wealth. 
Figure 18: Aggregate response to a monetary shock with lump-sum profits
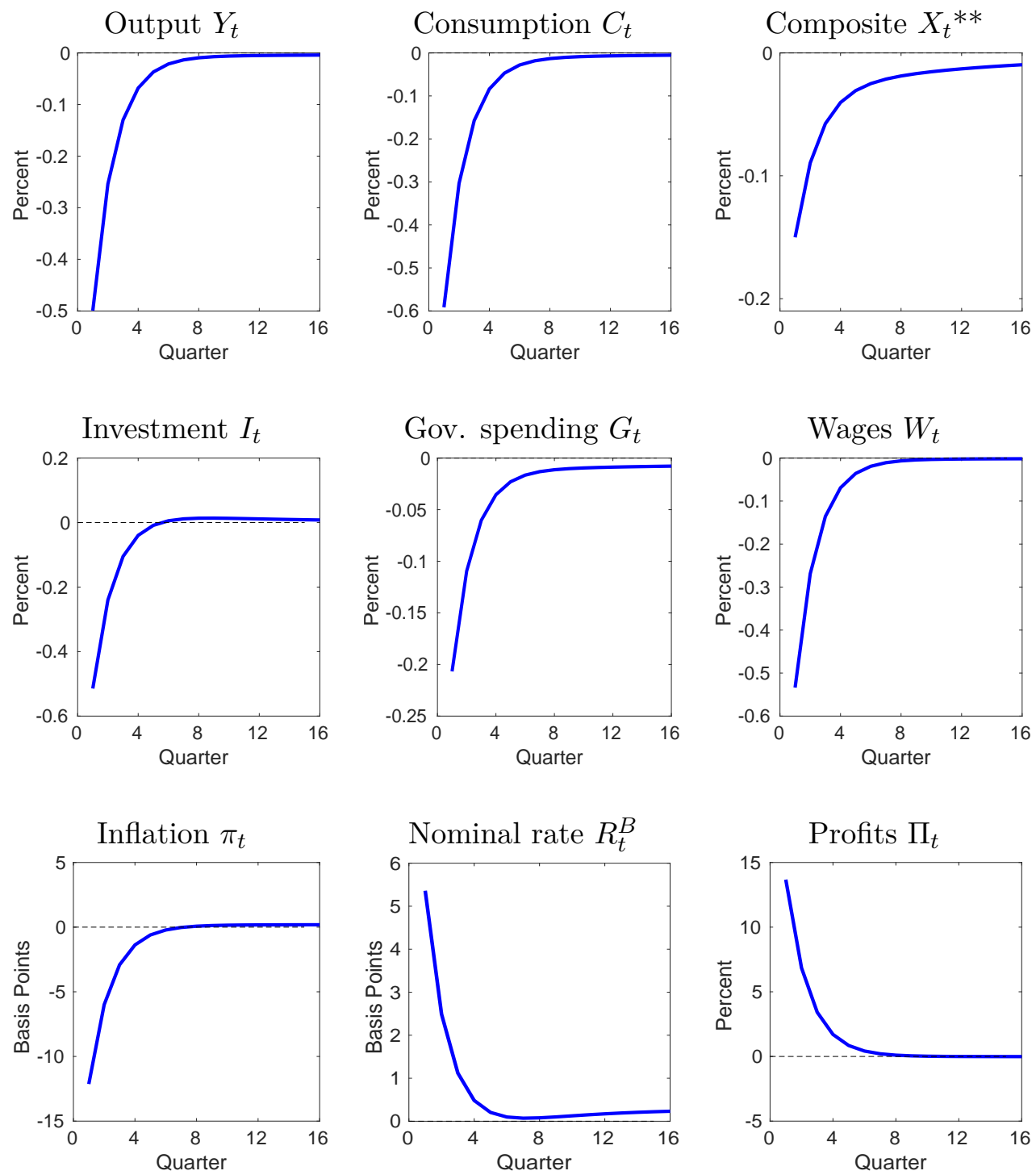

Price of capital $q_{t}$

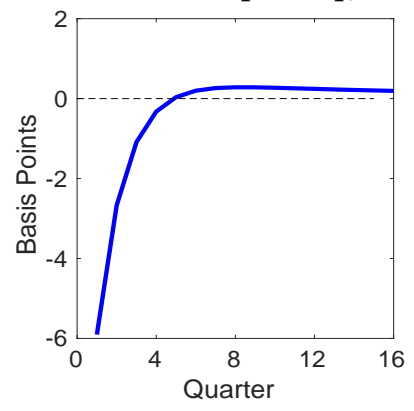

Dividend $r_{t}$

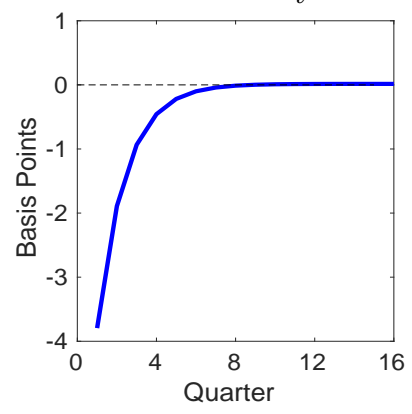

Liquidity premium*

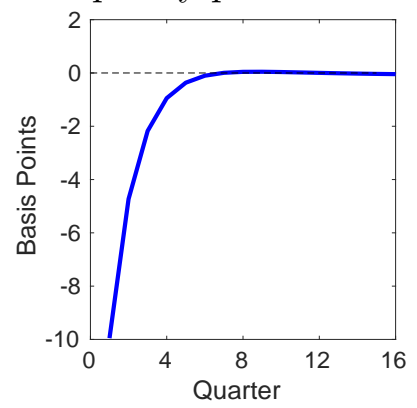

Notes: Impulse responses to a 1 standard deviation monetary policy shock, $\epsilon^{R}=36$ basis points (annualized). All rates (dividends, interest, liquidity premium) are not annualized. ${ }^{*} L P=\frac{E_{t} q_{t+1}+r_{t}}{q_{t}}-\frac{R_{t}^{B}}{E_{t} \pi_{t+1}} * * X_{t}=\int\left(c_{i t}-h_{i t} \frac{n_{i t}^{1+\gamma}}{1+\gamma}\right) d i$ 


\section{F.4 Model without sticky prices}

Figure 19 plots the aggregate effects of a monetary tightening in the baseline model without sticky prices, $\kappa=0$. While inflation responds strongly in the first period, the monetary shock does not move the real interest rate that households face from period 1 onwards. Monetary policy still affects real variables through the interaction of the Fisher channel and heterogeneity in marginal propensities to invest. The ex-post redistribution through inflation from borrowers to savers leads to an investment boom because savers have higher marginal propensities to invest. Heterogeneity in marginal propensities to consume, on the other hand, does not affect output because falling prices restore any shortfall in demand. Overall, a monetary tightening leads to an expansion through the Fisher effect on investment when prices are flexible.

In a model with real debt, there is no redistribution through surprise inflation. In response to a monetary tightening, inflation falls until the Taylor rule undoes the increase in the nominal rate, and the real rate stays constant from period 1 onwards. The sizable movement of inflation, however, does not affect real variables because the Fisher channel is absent; see Figure 20. 
Figure 19: Aggregate response to a monetary shock without sticky prices
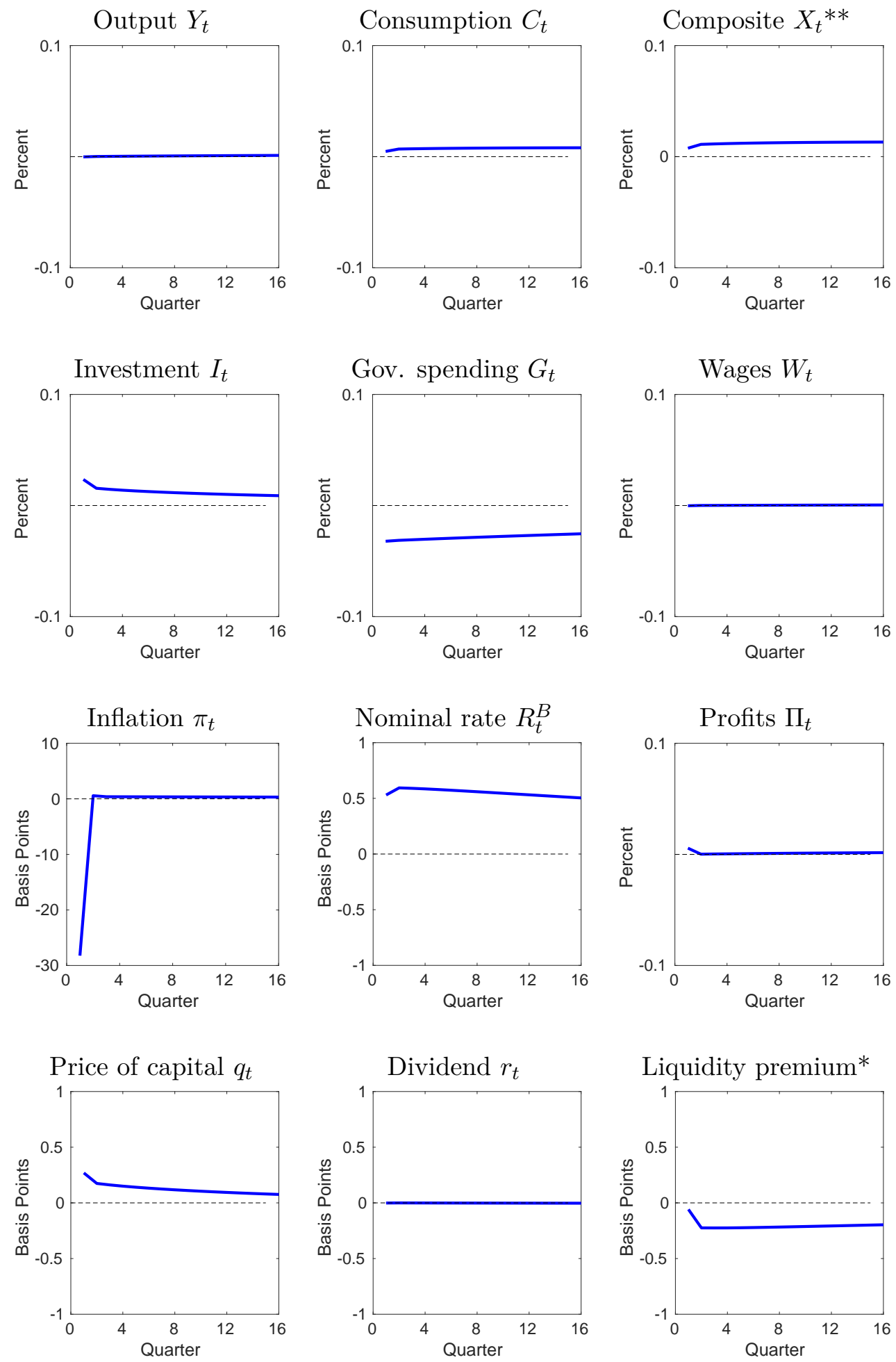

Notes: Impulse responses to a 1 standard deviation monetary policy shock, $\epsilon^{R}=36$ basis points (annualized). All rates (dividends, interest, liquidity premium) are not annualized. ${ }^{*} L P=\frac{E_{t} q_{t+1}+r_{t}}{q_{t}}-\frac{R_{t}^{B}}{E_{t} \pi_{t+1}} * * X_{t}=\int\left(c_{i t}-h_{i t} \frac{n_{i t}^{1+\gamma}}{1+\gamma}\right) d i$ 
Figure 20: Aggregate response to a monetary shock without sticky prices and real debt
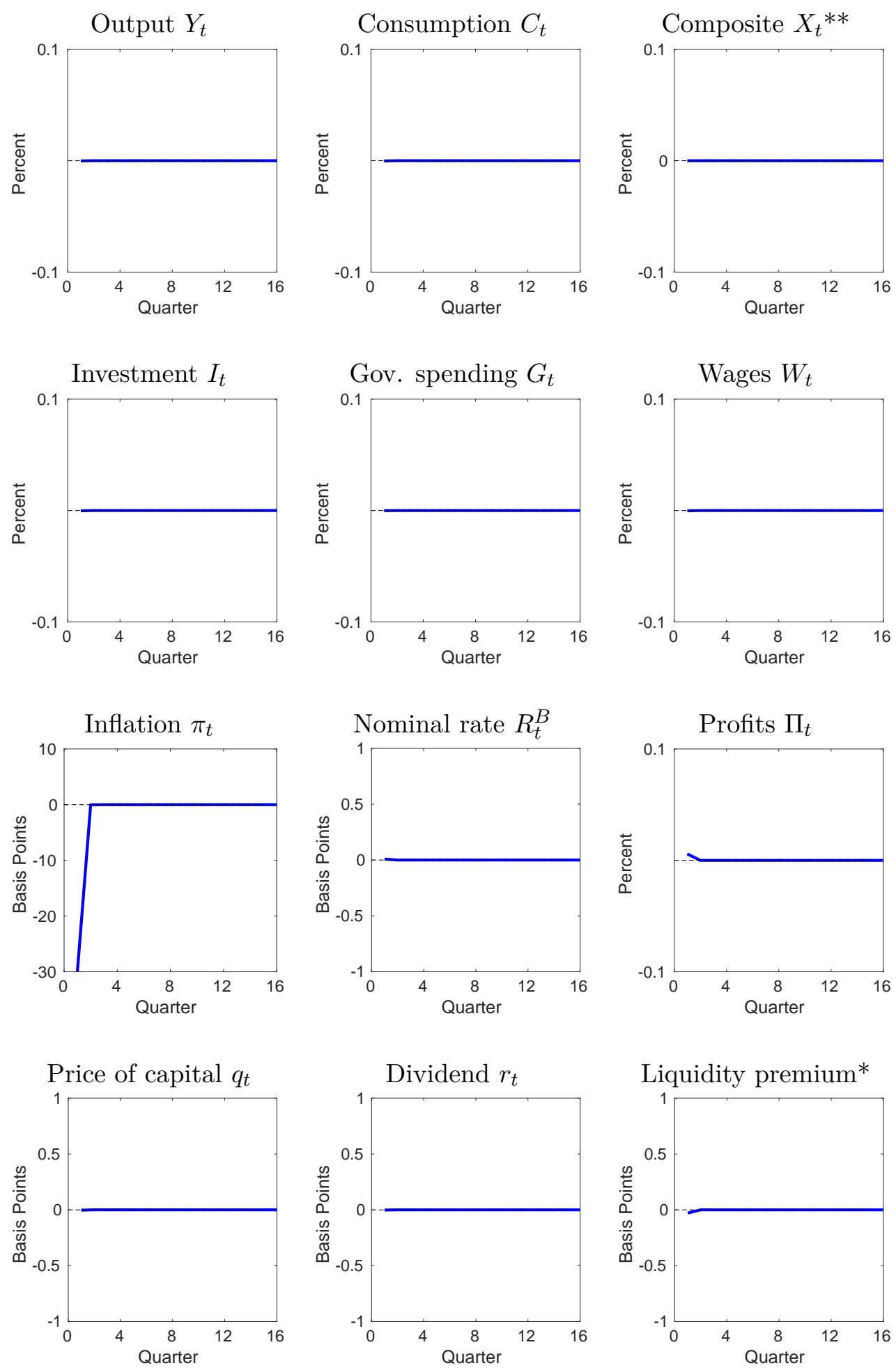

Liquidity premium*

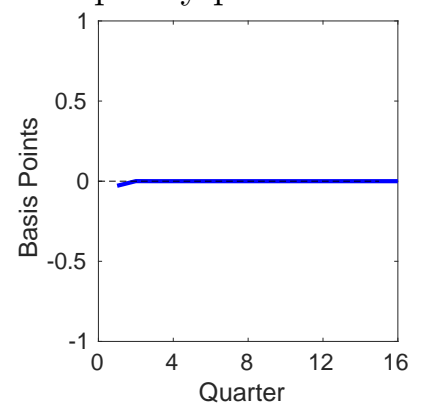

Notes: Impulse responses to a 1 standard deviation monetary policy shock, $\epsilon^{R}=36$ basis points (annualized). All rates (dividends, interest, liquidity premium) are not annualized. ${ }^{*} L P=\frac{E_{t} q_{t+1}+r_{t}}{q_{t}}-\frac{R_{t}^{B}}{E_{t} \pi_{t+1}} * * X_{t}=\int\left(c_{i t}-h_{i t} \frac{n_{i t}^{1+\gamma}}{1+\gamma}\right) d i$ 


\section{F.5 Robustness to fiscal rules}

When markets are incomplete, Ricardian equivalence does not hold, and fiscal policy matters for the monetary transmission. A change in real rates affect the government budget constraint. In turn, the government may either change spending or taxes and do it now or in the future. The choice of fiscal rules matters because they affect different households who may differ in marginal propensities to consume and invest.

In the baseline model, I assume that most of the adjustment goes through government debt, and future government spending adjusts to bring debt back to steady state. In Figure 22, in contrast, I assume a balanced budget, $\rho_{B}=0$, and an immediate reaction of government spending. The substantial fall in government spending amplifies the recessionary effect of a monetary tightening. Additionally, the fall in output is driven to an even larger extent by consumption. Investment falls less than in the baseline. Alternatively, taxes may adjust to balance the budget as shown in Figure 23. In this case, consumption falls less and investment more relative to baseline. In comparison to complete markets, investment falls in both cases by around $50 \%$ less with heterogeneity in household portfolios. In both cases, the sign difference in the portfolio responses remains and the magnitude of the fall in portfolio liquidity even increases; see Figure 21.

Figure 21: Portfolio response, $\Delta\left(b_{i t} / k_{i t}\right)$, with balanced budget
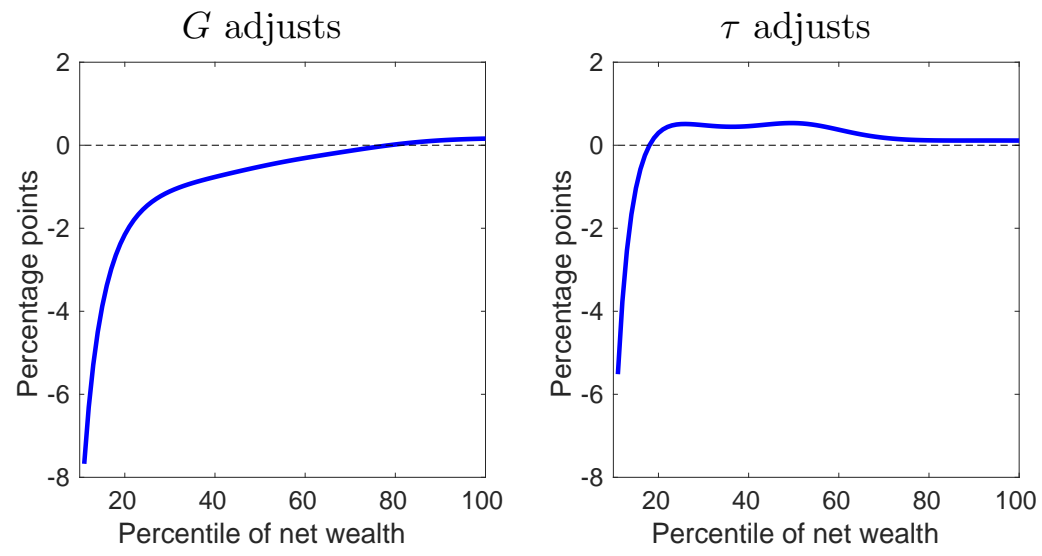

Notes: Change in portfolio liquidity after a 1 standard deviation monetary shock, $\epsilon^{R}=36$ basis points (annualized), after 2 years. Policies by wealth percentile are estimated using a local linear regression technique with a Gaussian kernel and a bandwidth of 0.1. Plotted from the 11th percentile onwards because poorer households hold negative liquid wealth. 
Figure 22: Aggregate response to a monetary shock with balanced budget by adjusting government spending
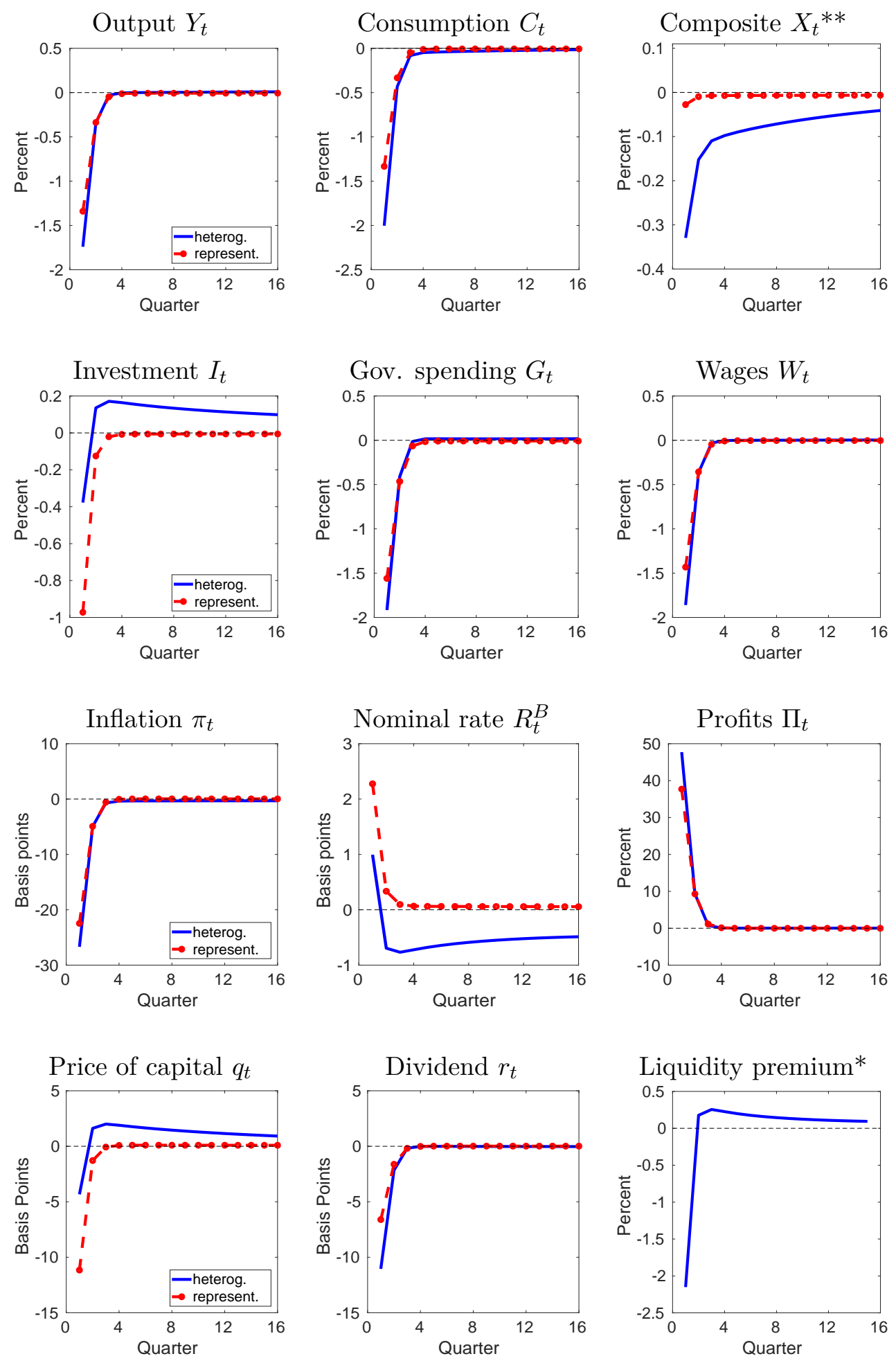

Notes: Impulse responses to a 1 standard deviation monetary policy shock, $\epsilon^{R}=36$ basis points (annualized). All rates (dividends, interest, liquidity premium) are not annualized. ${ }^{*} L P=\frac{E_{t} q_{t+1}+r_{t}}{q_{t}}-\frac{R_{t}^{B}}{E_{t} \pi_{t+1}} * * X_{t}=\int\left(c_{i t}-h_{i t} \frac{n_{i t}^{1+\gamma}}{1+\gamma}\right) d i$ 
Figure 23: Aggregate response to a monetary shock with balanced budget by adjusting the tax rate
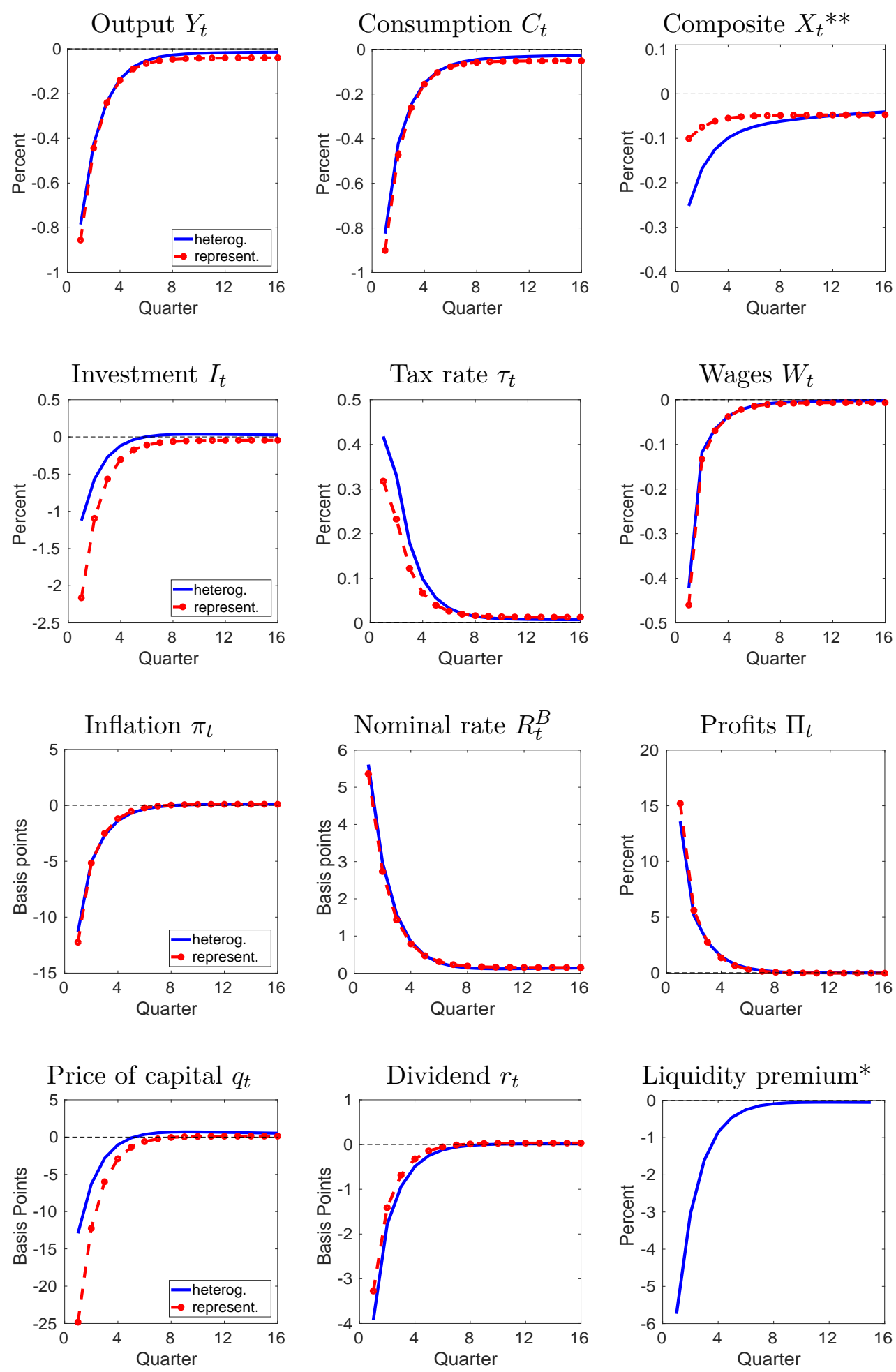

Liquidity premium*

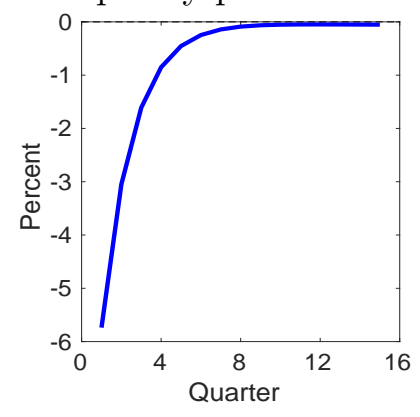

Notes: Impulse responses to a 1 standard deviation monetary policy shock, $\epsilon^{R}=36$ basis points (annualized). All rates (dividends, interest, liquidity premium) are not annualized. ${ }^{*} L P=\frac{E_{t} q_{t+1}+r_{t}}{q_{t}}-\frac{R_{t}^{B}}{E_{t} \pi_{t+1}} * * X_{t}=\int\left(c_{i t}-h_{i t} \frac{n_{i t}^{1+\gamma}}{1+\gamma}\right) d i$ 


\section{F.6 Response of the Model to TFP Shocks}

This section reports the aggregate effects of a TFP shock for comparison. I generate the IRFs by solving the model without monetary shocks but with time-varying total factor productivity in production, such that $Y_{t}=$ $Z_{t} F\left(K_{t}, L_{t}\right)$, where $Z_{t}$ is total factor productivity and follows an $\operatorname{AR}(1)$ process in logs. I assume a persistence of 0.9 and a standard deviation of 0.007. Additionally, I change the autocorrelation of government debt to $\rho_{B}=0.86$, which I estimate from the data.

Figure 24: Aggregate response to a TFP shock
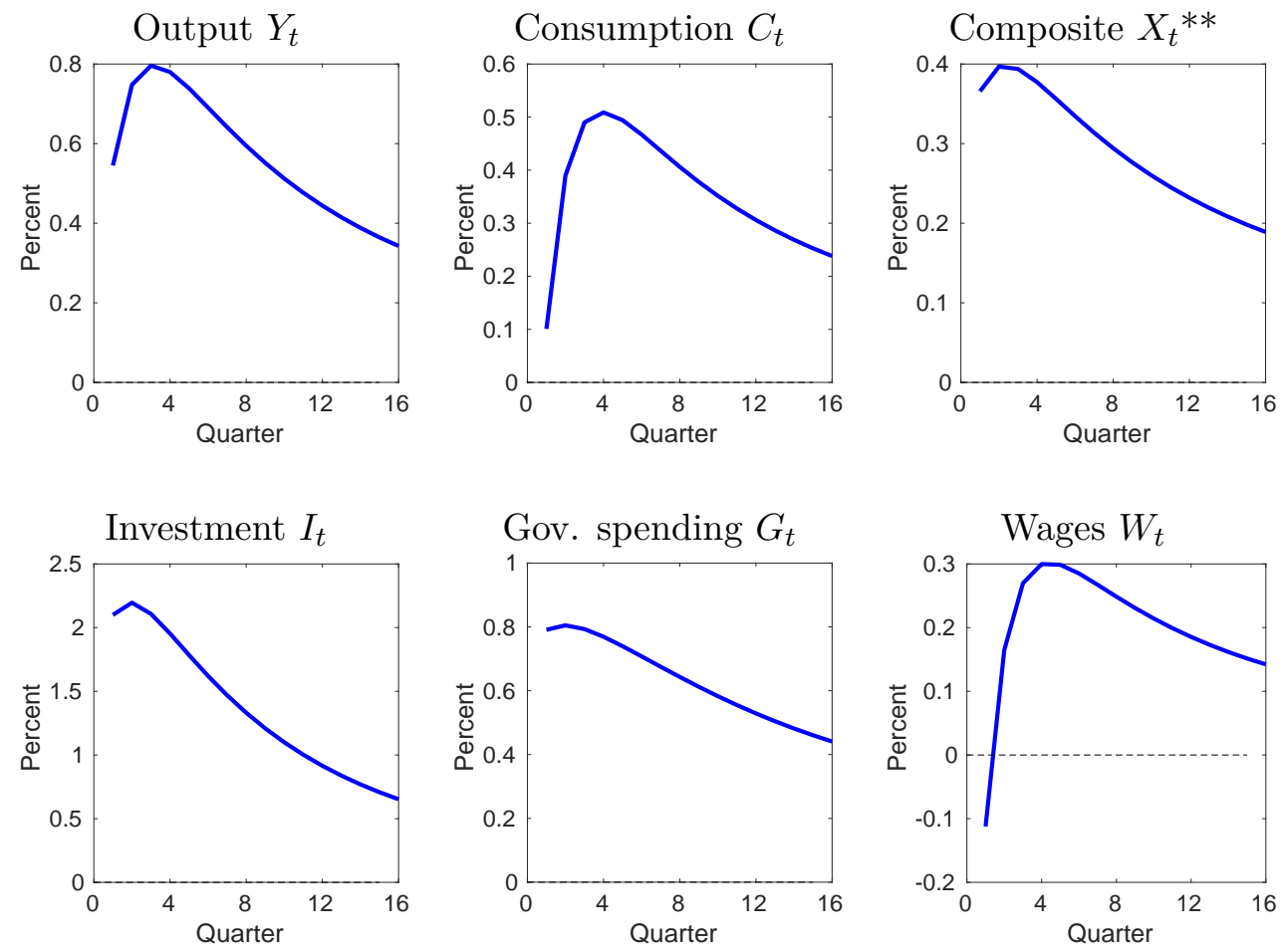

Notes: Impulse responses to a one standard deviation increase in TFP. 